\title{
Opening a New Time Window for Treatment of Stroke by Targeting HDAC2
}

\author{
Yu-Hui Lin, ${ }^{1,2 *}$ Jian Dong, ${ }^{1,2 *}$ Ying Tang, ${ }^{1,2}$ Huan-Yu Ni, ${ }^{1,2}$ Yu Zhang, ${ }^{1,2}$ Ping Su, ${ }^{2}$ Hai-Ying Liang, ${ }^{1,2}$ Meng-Cheng Yao, ${ }^{1,2}$ \\ Hong-Jin Yuan, ${ }^{1,2}$ Dong-Liang Wang, ${ }^{1,2}$ Lei Chang, ${ }^{1,2}$ Hai-Yin Wu, ${ }^{1,2}$ Chun-Xia Luo, ${ }^{1,2}$ and Dong-Ya Zhu ${ }^{1,2,3}$ \\ ${ }^{1}$ Institution of Stem Cells and Neuroregeneration, School of Pharmacy, Nanjing Medical University, Nanjing 211166, People's Republic of China, \\ ${ }^{2}$ Department of Pharmacology, School of Pharmacy, Nanjing Medical University, Nanjing 211166, People's Republic of China, and ${ }^{3}$ Key Laboratory of \\ Precision Medicine of Cardiovascular Disease, Nanjing Medical University, Nanjing 211166, People’s Republic of China
}

Narrow therapeutic window limits treatments with thrombolysis and neuroprotection for most stroke patients. Widening therapeutic window remains a critical challenge. Understanding the key mechanisms underlying the pathophysiological events in the peri-infarct area where secondary injury coexists with neuroplasticity over days to weeks may offer an opportunity for expanding the therapeutic window. Here we show that ischemia-induced histone deacetylase 2 (HDAC2) upregulation from 5 to $7 \mathrm{~d}$ after stroke plays a crucial role. In this window phase, suppressing HDAC2 in the peri-infarct cortex of rodents by HDAC inhibitors, knockdown or knock-out of $H d a c 2$ promoted recovery of motor function from stroke via epigenetically enhancing cells survival and neuroplasticity of surviving neurons as well as reducing neuroinflammation, whereas overexpressing HDAC2 worsened stroke-induced functional impairment of both WT and Hdac2 conditional knock-out mice. More importantly, inhibiting other isoforms of HDACs had no effect. Thus, the intervention by precisely targeting HDAC2 in this window phase is a novel strategy for the functional recovery of stroke survivors.

Key words: epigenetics; HDAC2; neuroplasticity; pharmacological target; stroke recovery; therapeutic time window

Significance Statement

Narrow time window phase impedes current therapies for stroke patients. Understanding the key mechanisms underlying secondary injury may open a new window for pharmacological interventions to promote recovery from stroke. Our study indicates that ischemia-induced histone deacetylase 2 upregulation from 5 to $7 \mathrm{~d}$ after stroke mediates the secondary functional loss by reducing survival and neuroplasticity of peri-infarct neurons as well as augmenting neuroinflammation. Thus, precisely targeting histone deacetylase 2 in the window phase provides a novel therapeutic strategy for stroke recovery.

\section{Introduction}

Stroke is a major public health problem leading to high rates of death and disability in adults (Mendis et al., 2015). Currently, thrombolysis with tissue plasminogen activator remains the only

Received Jan. 24, 2017; revised May 10, 2017; accepted June 1, 2017.

Author contributions: C.-X.L. and D.-Y.Z. designed research; Y.-H.L., J.D., Y.T., H.-Y.N., P.S., H.-Y.L., M.-C.Y., H.-J.Y., and D.-L.W. performed research; Y.Z., L.C., and H.-Y.W. contributed unpublished reagents/analytic tools; Y.-H.L., J.D., Y.T., H.-Y.N., P.S., and H.-Y.L. analyzed data; D.-Y.Z. wrote the paper.

This work was supported by National Natural Science Foundation of China Grants 91232304, 31530091, 81571188, and 81222016, National Basic Research Program of China 973 Program 2011CB504404, Natural Science Foundation of Jiangsu Province BK2011029 and Distinguished Young Scientists Fund BK20130040, and the Collaborative Innovation Center for Cardiovascular Disease Translational Medicine. We thank Chun-Jie Zhao for the gift of EMX1-Cre mice.

The authors declare no competing financial interests.

*Y.-H.L. and J.D. contributed equally to this work.

Correspondence should be addressed to either Dr. D. Zhu or Dr. C. Luo, Institution of Stem Cells and Neuroregeneration, School of Pharmacy, Nanjing Medical University, Nanjing 211166, People's Republic of China. E-mail: dyzhu@njmu.edu.cn or chunxialuo@njmu.edu.cn.

D01:10.1523/JNEUROSCI.0341-17.2017

Copyright $\odot 2017$ the authors $\quad 0270-6474 / 17 / 376712-17 \$ 15.00 / 0$ globally approved treatment for ischemic stroke (Chapman et al., 2014), although many approaches have been tried in the attempt to reduce the devastating impact of stroke. Unfortunately, however, $<6 \%$ of all ischemic stroke patients are treated with tissue plasminogen activator (Levine et al., 2013), due to the narrow therapeutic window (Cronin et al., 2014), risk of symptomatic intracerebral hemorrhage, perceived lack of efficacy in certain high-risk subgroups, and a limited pool of neurological and stroke expertise in the community (Chapman et al., 2014). Thus, there is a great need to investigate options to treat those patients, representing the vast majority, in whom tissue plasminogen activator or interventional approaches are not feasible or contraindicated.

Neuroprotection is an alternative approach to thrombolysis. Over the past two decades, many molecular targets have been identified to achieve neuroprotection. Disappointingly, in clinical trials, promising preclinical studies of neuroprotectants have not been translated into positive outcomes (Moretti et al., 2015). Although reasons for the failures are exceedingly complex, nar- 
row therapeutic window, single target and disregard for repair (Xu and Pan, 2013; Lo, 2014; Moretti et al., 2015) may be critical, as reticular pathophysiological events occur in the peri-infarct area over days to weeks, including inflammation (Walsh et al., 2014), oxidant stress (Ohsawa et al., 2007), apoptosis (Broughton et al., 2009), and neuroplasticity-mediated circuit reorganization (Murphy and Corbett, 2009; Sigler et al., 2009).

Histone deacetylases (HDACs) target histones, regulate chromosome dynamics, control cellular gene expression (Robert et al., 2011), and contribute to multiple signaling pathways linked to neuronal plasticity (Gräff et al., 2014), cell survival (Nott et al., 2008), neuroinflammation (Bie et al., 2014), and oxidative stress (Shimazu et al., 2013; Peng et al., 2015). Thus, HDACs may play a critical role in mediating pathophysiological events in the periinfarct area after stroke.

\section{Materials and Methods}

Animals. HDAC2 $2^{\text {flox/flox }}$ mice (C57BL/6 background), exons 5 and 6 with loxP recombination sites, were generated and maintained at Model Animal Research Center of Nanjing University (Nanjing, China). Cortexspecific Hdac2 conditional knock-out (CKO) mice were obtained by crossing Emx1-CRE ${ }^{+/-}$mice (a gift from Prof. Chun-Jie Zhao, Southeast University, China) with $\mathrm{HDAC} 2^{\text {flox/flox }}$ mice, named them HDAC2 $2^{\text {flox/flox }}$-Emx1-Cre mice. Male young adult (6-7 weeks) C57BL/6 mice (from Model Animal Research Center of Nanjing University, China) and Sprague Dawley rats (9- to 10-week-old) (from Shanghai Slac Laboratory Animal) were used. Animals were maintained at controlled temperature $\left(20 \pm 2^{\circ} \mathrm{C}\right)$ and group housed them (12 h light-dark cycle) with access to food and water ad libitum. Every effort was made to minimize the number of animals used and their suffering. All animal experiments were conducted in accordance with the Institutional Animal Care and Use Committee of Nanjing Medical University.

Drugs. Reagents were purchased and used at the indicated final concentration. HDAC inhibitors: trichostatin A (TSA, Selleck; $0.5 \mu \mathrm{M}$ ), MGCD0103 (Selleck; $1 \mu \mathrm{M}$ or $10 \mathrm{mg} / \mathrm{kg}$, i.p.), TMP269 (Selleck; $10 \mu \mathrm{M}$ ), and suberoylanilide hydroxamic acid (SAHA) (Sigma; $10 \mu \mathrm{M})$. Standards of glutamate and GABA were purchased from Sigma. Stable labeled L-glutamic-2,3,3,4,4- $\mathrm{d}_{5}$ acid and $\gamma$-aminobutyric-2,2,3,3,4,4- $\mathrm{d}_{6}$ acid were purchased from Cambridge Isotope Laboratories and Sigma, respectively.

Recombinant virus production and their stereotaxic injection. The recombinant Ad-HDAC2-Flag and Ad-inactive-HDAC2-Flag were produced by GeneChem. To generate catalytically inactive HDAC2, the fusion protein of HDAC2 (amino acids $1-288$ ) and $\beta$-galactosidase (HDAC2-LacZ) was expressed via the adenovirus system. The coding sequences of mouse $H d a c 2$ and inactive $H d a c 2$ were amplified by RTPCR. The primers were as follows. For $H d a c 2$, forward: 5 '-CGG GTA CCG GTC GCC ACC ATG GCG TAC AGT CAA GGA G-3'; reverse: $5^{\prime}$-CGG AAT TCT CAC TTG TCA TCG TCA TCC TTG TAG TCA GGG TTG CTG AGT TGT TCT G-3'; for inactive $H d a c 2$, forward: $5^{\prime}$-GAG GAT CCC CGG GTA CCG GTC GCC ACC ATG GCG TAC AGT CAA GGA G-3'; reverse: 5' -TCA TCC TTG TAG TCG CTT TTG ACA GTT AGA TTG AAA C- $3^{\prime}$. The PCR fragments and the pDC315 plasmid were digested with AgeI and EcoRI, and ligated with T4 DNA ligase to produce pDC315-HDAC2-Flag or pDC315-inactive-HDAC2-Flag, which overexpress HDAC2 or inactive HDAC2 protein with a flag tag in the $\mathrm{C}$ terminal. The plasmid was used to transform competent DH5 $\alpha$ Escherichia coli bacterial strains for identification. Using $10 \mu \mathrm{l}$ Lipofectamine 2000 mixed with $50 \mu$ l DMEM, HEK293 cells were cotransfected with (5 $\mu \mathrm{g}$ pDC315-HDAC2-Flag or pDC315-inactive-HDAC2-Flag) and $5 \mu \mathrm{g}$ pBHG lox $\triangle \mathrm{E} 1,3$ cre plasmid as a helper plasmid to generate the recombinant adenovirus Ad-HDAC2-Flag and Ad-inactive-HDAC2-Flag, respectively. Fifty days later, supernatant was harvested from HEK293 cells. After $2 \times$ virus amplification, the supernatant was filtered at $0.45 \mu \mathrm{m}$ and purified using the adeno- $\mathrm{X}$ virus purification kit (BD Bioscience, Clontech). After resuspension, serially diluted adenovirus was used to transduce HEK293 cells. Seven days later, labeled HEK293 cells were counted to calculate the viral titer $\left(1.5 \times 10^{9}\right.$ virus particles per milliliters $)$.
For the generation of the AAV-CAG-EGFP-T2A-Cre and AAV-CAGEGFP strains, standard cloning procedures were used to subclone the EGFP-T2A-Cre or EGFP cassettes into the backbone of AAV-CAG-MCS expression plasmid. Following DNA sequencing screening, the AAV plasmid was packaged into AAV serotype 8 virus from Obio Technology, with titers of $7 \times 10^{12}$ virus particles per milliliters.

Adult male C57BL/6 mice and HDAC2 $2^{\text {flox/flox }}$ were anesthetized and viruses were stereotaxically injected into the site $(2 \mathrm{nl} / \mathrm{s}, 2 \mu \mathrm{l})$ with the following coordinates (from bregma): anteroposterior, $0 \mathrm{~mm}$; mediolateral, $-1.5 \mathrm{~mm}$; dorsovental, $1.3 \mathrm{~mm}$. Following injection, injection needles were left in place for $10 \mathrm{~min}$ to assure even distribution of the virus.

Photothrombotic model of stroke. Focal cortical ischemia was induced in mice by photothrombosis of cortical microvessels as described in detail previously (Lee et al., 2004; Clarkson et al., 2010). Briefly, mice were anesthetized with isoflurane and placed in a stereotaxic device. The skull was exposed by incising the midline, clearing connective tissue and keeping the surface dry. A cold light source (World Precision Instruments) attached to an opaque template with an opening for giving a 2-mmdiameter 12,000 lux illumination was positioned $1.5 \mathrm{~mm}$ lateral from bregma. Rose Bengal solution (Sigma; $100 \mathrm{mg} / \mathrm{kg}$, i.p.) was administered. Five minutes later, the brain was illuminated for $15 \mathrm{~min}$ through the intact skull. Through light excitation, singlet oxygen was generated from Rose Bengal, which damages and occludes vascular endothelium, leading to focal cortical stroke. Control mice received the same dose of Rose Bengal without illumination.

Middle cerebral artery occlusion (MCAO) model of stroke. To induce ischemia-reperfusion stroke, intraluminal MCAO was performed in rats as described previously (Zhou et al., 2010). Briefly, under ketamine anesthesia, a 4-0 surgical nylon monofilament with rounded tip was introduced into the left internal carotid artery through the external carotid stump, advanced $20-21 \mathrm{~mm}$ past the carotid bifurcation until a slight resistance was felt. The filament was left in place for $120 \mathrm{~min}$ and then withdrawn for reperfusion. Regional cerebral blood flow was monitored by a laser Doppler perfusion monitor (Moor Instruments) to ensure that the regional cerebral blood flow decreased by $85 \%-95 \%$. Sham-operated rats receive the same procedure with MCAO rats except that the occluding filament was inserted only $7 \mathrm{~mm}$ above the carotid bifurcation.

Cannula implantation and drug microinjection. The surgical procedure was the same as described above. Stainless-steel guide cannulae (26 gauge, $3.5 \mathrm{~mm}$, RWD Life Science) were implanted into the core of the infarction ( $1.5 \mathrm{~mm}$ lateral from bregma, and $1.0 \mathrm{~mm}$ vertical from the cortical surface) and fixed to the skull with adhesive luting cement and acrylic dental cement. Following surgery, a stainless-steel obturator was inserted into the guide cannula to avoid obstruction until microinjection was made. Mice were briefly head-restrained while the stainless-steel obturator was removed and an injection tube (30 gauge, $4.0 \mathrm{~mm}$, RWD Life Science) was inserted into the guide cannula. The injection tube was designed to protrude $0.5 \mathrm{~mm}$ from the tip of the catheter, thus penetrating into the penumbra. A dose of drugs was slowly infused at a flow rate of $0.2 \mu \mathrm{l}$ per min to a total volume of $2 \mu$ l. Following injection, the injection cannulae were left in place for $5 \mathrm{~min}$ to reduce backflow. The stainless-steel obturator was subsequently reinserted into the guide cannula.

Grid-walking task. A $12 \mathrm{~mm}$ square wire mesh with a grid area of $32 \times$ $20 \times 50 \mathrm{~cm}$ (length $\times$ width $\times$ height, for mice) or a $3 \mathrm{~cm}$ square wire mesh with a grid area of $60 \times 60 \times 60 \mathrm{~cm}$ (length $\times$ width $\times$ height, for rats) was manufactured as the apparatus to conduct the grid-walking task (Clarkson et al., 2010; Luo et al., 2014). A camera was positioned beneath the device to video footage to assess the stepping errors (foot faults). Each mouse was placed individually on the top of the elevated wire grid and allowed to freely move until at least 100 steps have been taken by the left forelimb. Analysis was performed offline by rater blind to group design. The total number of foot-fault and non-foot-fault steps for each limb were counted. A ratio between foot faults and total steps were calculated as follows: number of foot faults/(foot faults + number of non-foot-fault steps) $\times 100$. The differences between animals and trials in the degree of locomotion were excluded by calculating the ratio between foot faults and total steps taken. If a step was not providing support and the foot went through the grid hole, this was considered a fault. A step was also 
considered a foot fault if an animal was resting with the grid at the level of the wrist.

Spontaneous forelimb task (cylinder task). The use of forelimbs for vertical wall exploration was encouraged in the spontaneous forelimb task (Baskin et al., 2003). When placed in a Plexiglas cylinder $(15 \mathrm{~cm}$ in height with a diameter of $10 \mathrm{~cm}$ ), the mouse spontaneously stood up by pressing the cylinder wall with either one or both of its forelimbs. Each mouse was allowed to freely explore until at least 20 rears in the cylinder and videotaped. The video footage was analyzed offline by calculating the time (seconds) during each rear that each animal spent on either the right forelimb, the left forelimb, or on both forelimbs in a slow motion (onefifth real time speed). Only rears in which both forelimbs could be clearly seen were included in our analysis. The percentage of time spent on each limb was calculated, and these data were used to derive an asymmetry index as follows: (\% ipsilateral use) - (\% contralateral use).

In vitro studies. Embryonic cortices (E16) of C57BL/6 mice were isolated with standard procedures. Cortical neurons were plated at a density of $1 \times 10^{4}$ for morphological analysis and $1 \times 10^{5}$ for biochemical detection. Primary mouse cortical cultures (10-12 DIV) were treated with NMDA ( $25 \mu \mathrm{M}$, Sigma) (removed after $1 \mathrm{~h}$, and assessed $8 \mathrm{~h}$ later), a mixture of $\mathrm{H}_{2} \mathrm{O}_{2}(50 \mu \mathrm{M}$, Sigma) and peroxynitrite (30 $\mu \mathrm{M}$, Millipore) (removed after $1 \mathrm{~h}$, and assessed $8 \mathrm{~h}$ later) or a mixture of TNF $\alpha$ (200 $\mathrm{ng} / \mathrm{ml}$, Millipore), interleukin- $1 \beta$ (IL- $1 \beta, 10 \mathrm{ng} / \mathrm{ml}$, Millipore), and matrix metalloproteinase 9 (MMP9, $400 \mathrm{ng} / \mathrm{ml}$, Millipore) (assessed $24 \mathrm{~h}$ later). The equal volume of vehicle was added as control, except that degraded peroxynitrite ( $30 \mu \mathrm{M}$, Millipore) $+\mathrm{H}_{2} \mathrm{O}$ (the same volume as $\mathrm{H}_{2} \mathrm{O}_{2}$ ) were added as the control of peroxynitrite $+\mathrm{H}_{2} \mathrm{O}_{2}$.

Western blot analysis. Western blot analysis was performed as described in detail previously (Zhou et al., 2010). Briefly, peri-infarct cortex tissue was rapidly dissected around the stroke infarct core over the ice box as previously described (Clarkson et al., 2011). The equivalent region of cortex was taken in sham mice. Cellular sample was collected by scraping the bottom of the dish. The primary antibodies were as follows: rabbit anti-HDAC2 (1:2000; Abcam, catalog \#ab32117, RRID: AB_732777), rabbit anti-HDAC3 (1:2000; Abcam, catalog \#ab16047, RRID: AB_443297), rabbit anti-histone H4 (1: 500; Abcam, catalog \#ab10158, RRID: AB_296888), rabbit anti-acetylated histone H4 (acetyl-K5) (1:1000; Abcam, catalog \#ab51997, RRID: AB_2264109), mouse anti-Flag (1:1000; Sigma, catalog \#F1804, RRID: AB_262044), rabbit anti-Bestrophin1 (1:500; Abcam, catalog \#ab14927, RRID: AB_301518), rabbit anti-UNC5C (1:2000; Abcam, catalog \#ab179688, RRID: AB_2632588), rabbit anti-DISC1 (1:2000; Abcam, catalog \#ab192258, RRID: AB_2632589), rabbit anti-NOVA1 (1: 2000; Abcam, catalog \#ab183024, RRID: AB_2632587), rabbit antiTNF $\alpha$ (1:500; Abcam, catalog \#ab9739, RRID: AB_308774), rabbit anti-IL-1 $\beta$ (1:500; Abcam, catalog \#ab9787, RRID: AB_308787), or rabbit anti-BDNF (1:2000; Abcam, catalog \#ab108383, RRID: AB_10858252). Mouse anti-GAPDH (1:4000; Kangchen Biotech, catalog \#KC-5G4, RRID: AB_2493106) or mouse anti- $\beta$-actin (1:4000; Sigma, catalog \#A1978, RRID: AB_476692) was used as internal control. Appropriate HRP-linked secondary antibodies were used for detection by enhanced chemiluminescence (Pierce).

Immunostaining, imaging, and analysis. The details of immunofluorescence for brain section and cultured cells have been reported previously (Luo et al., 2010). Immunocytochemistry and immunohistochemistry on different experimental conditions were performed with the same antibody solution at the same time to assure identical staining conditions. In brief, for immunohistochemistry, mice were transcardially perfused with $0.9 \% \mathrm{NaCl}$ followed by $4 \%$ PFA under deep anesthesia (ketamine), and their brains were sectioned at $40 \mu \mathrm{m}$ thickness using a vibratome (VT1200s, Leica). For immunocytochemistry, cells were fixed using $4 \%$ PFA. Slices/cells were blocked in PBS containing 3\% normal goat serum, $0.3 \%(\mathrm{w} / \mathrm{v})$ Triton $\mathrm{X}-100$, and $0.1 \%$ BSA at room temperature for $1 \mathrm{~h}$, followed by incubation in primary antibody at $4^{\circ} \mathrm{C}$ overnight. The primary antibodies were used as follows: rabbit-anti HDAC2 (1:1000; Abcam, catalog \#ab32117, RRID: AB_732777), mouse-anti-NeuN (1: 500; Millipore, catalog \#MAB377, RRID: AB_2298772), and rabbit-anti Iba1 (1:300; Wako, catalog \#019-19741, RRID: AB_839504). Secondary antibodies used were goat-anti mouse Cy3 (1:200; Jackson ImmunoResearch Laboratories, catalog \#115-165-003, RRID: AB_2338680), goat-anti mouse Alexa-488 (1:400; Jackson ImmunoResearch Laboratories, catalog \#115-545-003, RRID: AB_2338840), goat-anti rabbit Cy3 (1:200; Jackson ImmunoResearch Laboratories, catalog \#111-165-003, RRID: AB_2338000), goat-anti rabbit Alexa-488 (1:400; Jackson ImmunoResearch Laboratories, catalog \#111-545-003, RRID: AB_2338046), and goat-anti rabbit Alexa647 (1:300; Jackson ImmunoResearch Laboratories, catalog \#111-605-003, RRID: AB_2338072). Finally, cultures were counterstained with Hoechst 33258 (Sigma) to label the nuclei. Images were captured with a fluorescence microscope (Axio Imager, Carl Zeiss) or a confocal laser-scanning microscope (LSM700, Carl Zeiss) at identical settings for each of conditions. Images were quantified using ImageJ $1.42 \mathrm{q}$ by an experimenter blind to treatment groups. For brain slice NeuN and Ibal staining, the number of NeuN-positive cells and amoeboid microglia in the peri-infarct area between different experimental conditions use identical intensity settings. Four directions (2 o'clock, 4 o'clock, 8 o'clock, 10 o'clock) were selected to capture the peri-infarct area in one slice; three typical slices were chosen to represent an animal. Neuron and amoeboid microglia density was calculated from the number of NeuN-positive cells and amoeboid microglia divided by peri-infarct area, respectively. For brain slices with GFP and HDAC2 costainings, the settings were the same in each experimental condition.

HDAC activity assay. HDAC activity in peri-infarct cortical samples was measured by a HDAC fluorometric assay kit (EMD Millipore). For HDAC2- or HDAC4,5,7-specific activity, immunoprecipitation with specific antibody was performed before the assay as described previously (Nott et al., 2008). In brief, tissue lysates prepared in immunoprecipitation buffer ( $50 \mathrm{~mm}$ Tris- $\mathrm{HCl}, 150 \mathrm{~mm} \mathrm{NaCl}, 5 \mathrm{~mm}$ EDTA, $0.5 \% \mathrm{NP}-40$, $\mathrm{pH}$ 8.0, supplemented with $1 \mathrm{~mm}$ PMSF) were incubated with $1 \mu$ l mouse anti-HDAC2 (Abcam, catalog \#ab51832, RRID: AB_880350) or $4 \mu \mathrm{l}$ rabbit anti-HDAC4,5,7 (Santa Cruz Biotechnology, catalog \#sc-11421, RRID: AB_647888), and $20 \mu$ l protein G-Agarose (Sigma) overnight on a tube rotator at $4^{\circ} \mathrm{C}$. Then beads were centrifuged at $5000 \times g$ and washed five times in PBS. HDAC assay substrate was added to the beads and incubated at $30^{\circ} \mathrm{C}$ for $40 \mathrm{~min}$. Finally, activator solution containing TSA (HDAC inhibitor) was used to stop the reaction, and the supernatant was used for fluorescent measurement. Fluorescent was measured in 384well plate by excitation wavelength $360 \mathrm{~nm}$ and emission wavelength 450 $\mathrm{nm}$ using a flourescence plate reader (Molecular Devices). HDAC activity was normalized to total protein levels determined by Bradford assay.

In vivo microdialysis. Microdialysis in the peri-infarct cortex was performed as reported previously with some modifications (Jo et al., 2014). Mice were kept under isoflurane anesthesia (1.5\%) and mounted in a stereotaxic frame (Kopf). After exposing the skull and drilling a burr hole, a CMA7 microdialysis probe of concentric design (CMA Microdialysis) was positioned and inserted into the peri-infarct area with the following coordinates (from bregma): anteroposterior, $0 \mathrm{~mm}$; mediolateral, $-0.65 \mathrm{~mm}$; dorsovental, $1.5 \mathrm{~mm}$. The probe was connected to a 100 $\mu \mathrm{l}$ microsyringe (Hamilton) controlled by a microperfusion pump (WPI) with polyethylene (PE-20) and perfused with ASCF composed of the following (in mM): $\mathrm{Na}^{+} 151.1, \mathrm{~K}^{+} 2.6, \mathrm{Mg}^{2+} 0.9, \mathrm{Ca}^{2+} 1.3, \mathrm{Cl}^{-}$ $122.7, \mathrm{HCO}_{3}^{-} 21.0, \mathrm{HPO}_{4}^{2-} 2.5$, and glucose 3.87 at a speed of $1 \mu \mathrm{l} / \mathrm{min}$. Perfusates from the outlet end of the tubing were collected in plastic vials standing in ice. Samples were collected over 20 min intervals for $2 \mathrm{~h}$. The second dialysate was used for measurement of L-glutamate and GABA.

GABA and L-glutamate measurement. The concentrations of GABA and glutamate in dialysates were analyzed using ion pairing HPLC with positive electrospray LC-MS/MS as described previously with some modifications (Eckstein et al., 2008). Stock solutions of $100 \mu \mathrm{g} / \mathrm{ml}$ were prepared in HPLC-grade water for GABA, glutamate, [D6]-GABA, and [D5]-glutamate. All further standards were obtained by diluting the stock solutions with ACSF. Internal standard working solution (500 $\mathrm{ng} / \mathrm{ml}$ of [D6]-GABA and $2.5 \mu \mathrm{g} / \mathrm{ml}$ [D5]-glutamate) were obtained by diluting the stock solutions with acetonitrile. A total of $20 \mu \mathrm{l}$ of the internal standard working solution was added to $20 \mu \mathrm{l}$ of microdialysis or standard sample; then $10 \mu \mathrm{l}$ of the homogenized mixing solution was injected into the LC-MS/MS. The solution was analyzed by HPLC-MS using a 6410 Triple Quad LC/MS mass spectrometer (Agilent Technologies) coupled to a 1200 Series HPLC system (Agilent Technologies). Analyte separation was achieved using a SeQuant ZIC-HILIC column 
(Merck, $3.5 \mu \mathrm{m}, 20 \times 2.1 \mathrm{~mm}$ ). Mobile phases A and B were composed of $1 \%$ formic acid in HPLC grade water and acetonitrile, respectively. The gradient elution profile was chosen as follows: $0 \mathrm{~min}: 15 \% \mathrm{~A}(0.4 \mathrm{ml} /$ $\min ) ; 0.20 \mathrm{~min}: 95 \% \mathrm{~A}(0.4 \mathrm{ml} / \mathrm{min}) ; 3.00 \mathrm{~min}: 95 \% \mathrm{~A}(0.4 \mathrm{ml} / \mathrm{min}) ; 3.5$ min: $15 \%$ A (0.4 ml/min); $10 \mathrm{~min}: 15 \% \mathrm{~A}(0.4 \mathrm{ml} / \mathrm{min})$. We performed MS/MS analysis in the positive mode with an ESI with a dwell time of 100 $\mathrm{ms}$. The ion spray voltage was set at $4000 \mathrm{~V}$, the source temperature at $350^{\circ} \mathrm{C}$, the gas flow at $10 \mathrm{~L} / \mathrm{min}$, and the nebulizer pressure at $35 \mathrm{psi}$. The positive charged molecular ions $\mathrm{m} / \mathrm{z} 104.1$ and 148.1 for GABA and glutamate were generated, respectively. Multiple reaction monitoring mode was used. Two transitions were measured for determination of GABA and glutamate, whereas one transition was used for quantification. For the internal standards [D6]-GABA and [D5]-glutamate, one transition was selected. The collision energy offset was $15,14,12$, and 4 for [D5]-glutamate, glutamate, [D6]-GABA, and GABA, respectively. The specific ions $(\mathrm{m} / \mathrm{z})$ monitored were glutamate $(\mathrm{m} / \mathrm{z} 148.1 \rightarrow \mathrm{m} / \mathrm{z}$ 84.1), GABA $(\mathrm{m} / \mathrm{z} 104.1 \rightarrow \mathrm{m} / \mathrm{z} 87.1)$, [D5]-glutamate $(\mathrm{m} / \mathrm{z} 153.1 \rightarrow \mathrm{m} / \mathrm{z}$ $88.1)$, and [D6]-GABA $(\mathrm{m} / \mathrm{z} 110.1 \rightarrow \mathrm{m} / \mathrm{z}$ 93.2). All data were collected and analyzed using Mass Hunter Workstation Software, version B.02.00 (Agilent Technologies).

Gene expression analyses. RNA sequencing was performed by CapitalBio Technology. Briefly, total mRNA was isolated from peri-infarct tissues using the Trizol reagent (Invitrogen) and purified with mirVana miRNA Isolation Kit (Ambion) according to the manufacturer's protocol. Total RNA was quality-controlled using a spectrophotometer (NanoDrop ND-1000). RNA integrity was determined by capillary electrophoresis using the RNA 6000 Nano Lab-on-a-Chip kit and the Bioanalyzer 2100 (Agilent Technologies). Only RNA extracts with RNA integrity number values $>6$ underwent in further analysis. The array data were analyzed for data summarization, normalization, and quality control by using the GeneSpring software, version 13 (Agilent Technologies). Significant differential expression between sample sets was defined as probes that exhibited a robust fold change of $\geq 2.0(\mathrm{Fc} \geq 2.0)$ with an adjusted $p$ value of $\leq 0.05$. Three samples from vehicle and MGCD0103 were compared. The data were $\log 2$ transformed and median centered by genes using the Adjust Data function of Cluster 3.0 software then further analyzed with hierarchical clustering with average linkage. Finally, we performed tree visualization by using Java Treeview (Stanford University School of Medicine, Stanford, CA). Differentially expressed genes were further analyzed by gene ontology and pathway analysis. Statistical tests were performed using Student's $t$ test and the BenjaminiHochberg false discovery rate to account for multiple comparisons.

Chromatin immunoprecipitation protocol. Chromatin immunoprecipitation assays were performed according to the manufacturer's protocol (EMD Millipore). In brief, $37 \%$ formaldehyde (1\% final concentration) was added directly to the homogenate of peri-infarct tissue for $15 \mathrm{~min}$ at $37^{\circ} \mathrm{C}$ to cross-link DNA and its associated proteins. The cross-link reaction was then quenched with glycine $(0.125 \mathrm{M}$ final concentration) for $5 \mathrm{~min}$. We used a Branson Digital Sonifier 450 and sonicated at $45 \%$ maximum amplitude for twenty-five $20 \mathrm{~s}$ pulses ( $50 \mathrm{~s}$ pause between pulses) at $4^{\circ} \mathrm{C}$ while samples were immersed in an ice bath to shear the DNA to a size between 200 and $1000 \mathrm{bp}$. Cell debris was removed by centrifugation, and supernatants were diluted with chromatin immunoprecipitation dilution buffer. A fraction of the diluted supernatant was used for immunoprecipitation input control. The remainder was subjected to preclearing by incubation with Protein A-Sepharose beads for $30 \mathrm{~min}$ at $4^{\circ} \mathrm{C}$, followed by immunoprecipitation overnight using antibody against acetylated histone H4 (Abcam, catalog \#ab51997, RRID: AB_2264109). Immune complexes were collected by incubation with Protein A-Sepharose beads for $1 \mathrm{~h}$ at $4^{\circ} \mathrm{C}$. Beads were collected and subjected to a series of sequential washes. Bound complexes were eluted from the beads by vortexing in elution buffer containing 1\% SDS and $0.1 \mathrm{M} \mathrm{NaHCO}_{3}$, and crosslinking was reversed by incubation overnight at $65^{\circ} \mathrm{C}$. Purified DNA samples were normalized and subjected to real-time PCR for 45 cycles, using primer pairs specific for 150-250 bp segments corresponding to mouse gene promoter regions (regions upstream of the start codon, near the first exon).

Real-time PCR. Real-time PCR was performed with SYBR-Greenbased reagents (FastStart Universal SYBR Green master; Roche), us- ing a Lightcycler96 real-time PCR Detection system (Roche). The relative quantities of immunoprecipitated DNA fragments were calculated by using the comparative $\mathrm{C}_{\mathrm{T}}$ method. All reactions were performed in triplicate. Primer sequences used for PCR were as follows: Discl forward, CCTGGTAAGAGGCAACTGCT, Disc1 reverse, CGTCATAACCTCGCCTCTGG; Unc5c forward, ACAGAAGCGCAAGGATCAGA, Unc5c reverse, GGAAGTGCTGGGAGGTGTAG; and Noval forward, GCTCATTCACTCCCGCTCTG, Nova1 reverse, CGAGCAGTGTGGCTGATGTG.

Slice preparation. Photothrombotic stroke mice receiving drugs or vehicle through cannulae 5-7 d after stroke (once a day) were anesthetized with ethyl ether and decapitated at $8 \mathrm{~d}$ after stroke. Following decapitation, brains were rapidly removed and placed into ice-cold cutting solution containing $110 \mathrm{~mm}$ choline chloride, $20 \mathrm{~mm}$ glucose, $2.5 \mathrm{~mm} \mathrm{KCl}, 0.5$ $\mathrm{mm} \mathrm{CaCl}, 7 \mathrm{~mm} \mathrm{MgCl}_{2}, 1.3 \mathrm{~mm} \mathrm{NaH} \mathrm{PO}_{4}, 25 \mathrm{~mm} \mathrm{NaHCO}, 1.3 \mathrm{~mm}$ $\mathrm{Na}$-ascorbate, and $0.6 \mathrm{~mm} \mathrm{Na}$-pyruvate. Cortical slices $(350 \mu \mathrm{m})$ were cut using a vibrating blade microtome (VT1200s, Leica) and transferred to an interface-style chamber containing normal ACSF composed of 10 mu glucose, $125 \mathrm{~mm} \mathrm{NaCl}, 2.5 \mathrm{~mm} \mathrm{KCl}, 2 \mathrm{~mm} \mathrm{CaCl}_{2}, 1.3 \mathrm{~mm} \mathrm{MgCl}$, 1.3 mм NaH $\mathrm{PO}_{4}, 25 \mathrm{~mm} \mathrm{NaHCO}_{3}, 1.3 \mathrm{~mm} \mathrm{Na}$-ascorbate, and $0.6 \mathrm{~mm} \mathrm{Na}$ pyruvate. Slices were recovered at $34^{\circ} \mathrm{C}$ for at least $1 \mathrm{~h}$ before recording. All solution was gassed with $95 \% \mathrm{O}_{2}-5 \% \mathrm{CO}_{2}$.

Tonic inhibitory current and mean phasic current recording. $\mathrm{GABA}_{\mathrm{A}}$ receptor-mediated tonic current in peri-infarct pyramidal neurons was measured as previously described (Clarkson et al., 2010). Slices were transferred to a recording chamber that was continuously perfused with oxygenated ACSF (4-6 ml/min). Neurons were viewed under upright microscopy (Olympus X51W, Nomasky) and recorded with Axonpatch700B amplifier (Axon Instruments). Control recordings were made from similar location neurons from sham-operated mice. The holding potential was $10 \mathrm{mV}$. Microelectrode resistance was typically $6-8 \mathrm{M} \Omega$, and the pipette was filled with an internal solution: $120 \mathrm{~mm} \mathrm{CsMeSO}_{4}, 10 \mathrm{mM}$ CsCl, 5 mm TEA-Cl, 1.5 mm $\mathrm{MgCl}_{2}, 10$ mM HEPES, 0.1 mM EGTA, 2 mM Na-ATP, 0.5 mm Na-GTP, and 5 mM QX-314, pH 7.25-7.30 with CsOH, 275-285 mOsmol. GABA was added to the recording ACSF to a final concentration of $5 \mu \mathrm{M}$ to replenish the extracellular GABA concentration reduced by the high-flow perfusion of the slices. Data were low-pass filtered at $2 \mathrm{kHz}$ and acquired at $5-10 \mathrm{kHz}$. The series resistance $(\mathrm{R})$ was always monitored during recording for fear of that reseal of ruptured membrane would cause change of both kinetics and amplitude. Cells in which the R or capacity deviated by $20 \%$ from initial values, or $\mathrm{R}>20$ $\mathrm{M} \Omega$ at any time during the recording were excluded from the analysis. Data were collected with pClamp 10.3 software and analysis using Clampfit 10.3 (Molecular Devices). The amplitude of tonic GABA current was recorded as the reduction in baseline holding currents after bath-applying bicuculline $(100 \mu \mathrm{M})$. Tonic current density was calculated from the current amplitude divided by the membrane capacity. Amplitude and frequency of spontaneous IPSCs (sIPSCs) before bicuculline administration were analyzed using Mini software (http://www. synaptosoft.com/MiniAnalysis/, RRID: SCR_002184). All experiments were performed by a person unaware of treatment groups.

Neuronal resting membrane potential and GABA reversal potential determination. Cell-attached recording technique was used to estimate neuronal resting membrane potential $\left(\mathrm{V}_{\text {rest }}\right)$ and GABA reversal potential $\left(\mathrm{E}_{\mathrm{GABA}}\right)$ as described previously (Ge et al., 2006; Clarkson et al., 2010). Microelectrode internal solution was composed of $120 \mathrm{~mm}$ potassium gluconate, $15 \mathrm{~mm} \mathrm{KCl}, 4 \mathrm{~mm} \mathrm{MgCl}_{2}, 0.1$ mм EGTA, 10 mм HEPES, $4 \mathrm{~mm}$ MgATP, $0.3 \mathrm{~mm} \mathrm{Na}_{3} \mathrm{GTP}$, and $7 \mathrm{~mm}$ phosphocreatine. The junction potential between pipette and extracellular solution was nulled by the voltage-offset of the amplifier before establishing the seal and was not corrected. Depolarizing voltage ramps ( -100 to $100 \mathrm{mV}$ ) were applied to activate voltage-gated $\mathrm{K}^{+}$channels and establish the $\mathrm{K}^{+}$current reversal potential, which provides a measure of the $\mathrm{V}_{\text {rest }}$, given near equimolar $\mathrm{K}^{+}$inside the cell and the pipette. $\mathrm{E}_{\mathrm{GABA}}$ was estimated by measuring the $\mathrm{K}^{+}$reversal potential after activating $\mathrm{GABA}_{\mathrm{A}}$ receptors with $50 \mu \mathrm{M}$ muscimol. Between stimulations, the patch was hold at $-65 \mathrm{mV}$ hyperpolarized with respect to $V_{\mathrm{m}}$ to remove possible voltage-dependent "steady-state" inactivation from the $\mathrm{K}(\mathrm{V})$ channel at the physiological $V_{\mathrm{m}}$. For analysis of currents evoked by ramp stimulation, a correction 
A

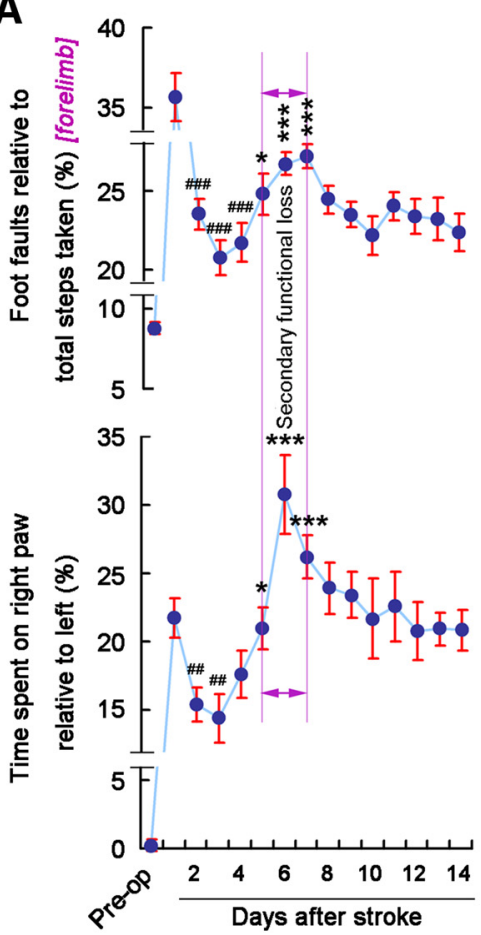

B

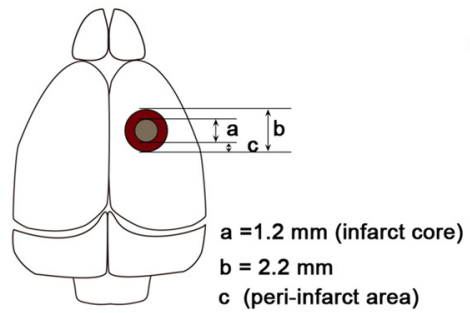

C

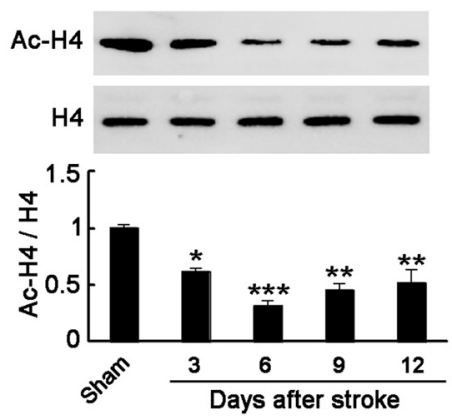

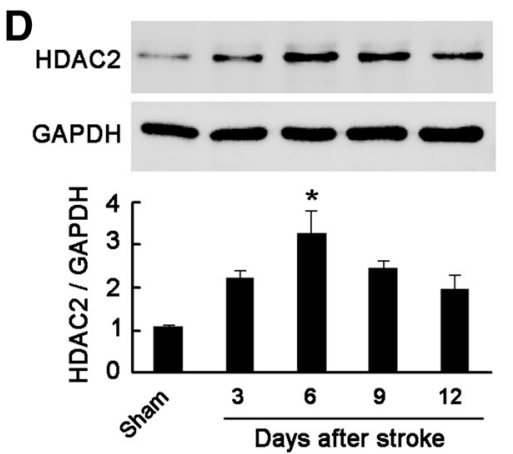

E

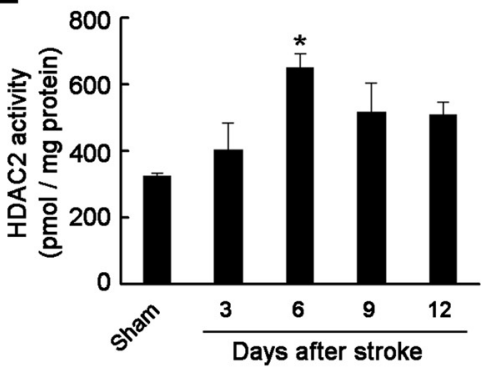

$F$
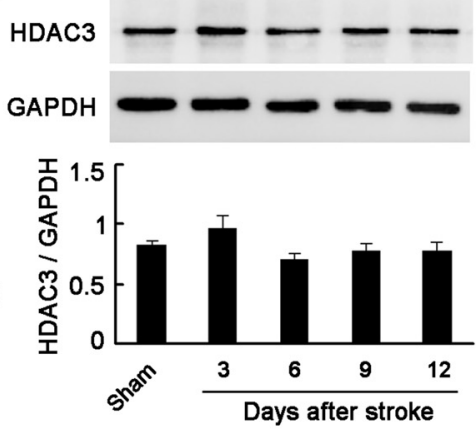

G

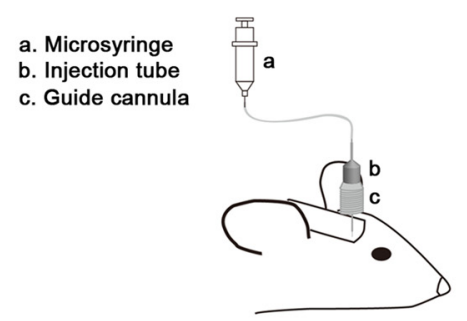

H

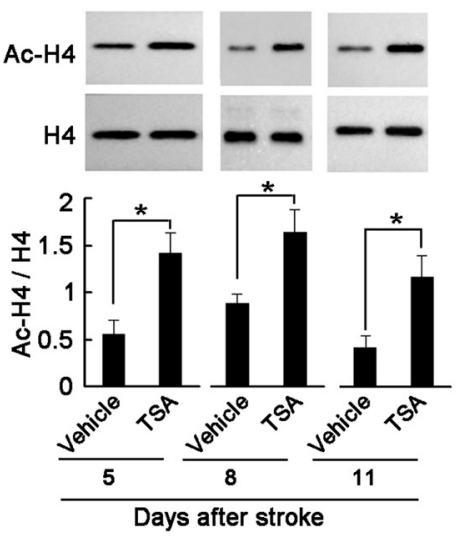

I

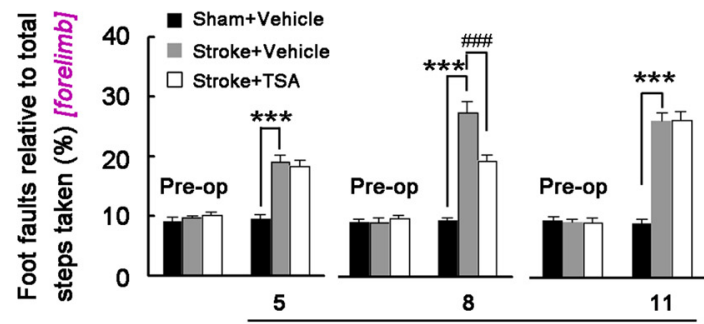

Days after stroke

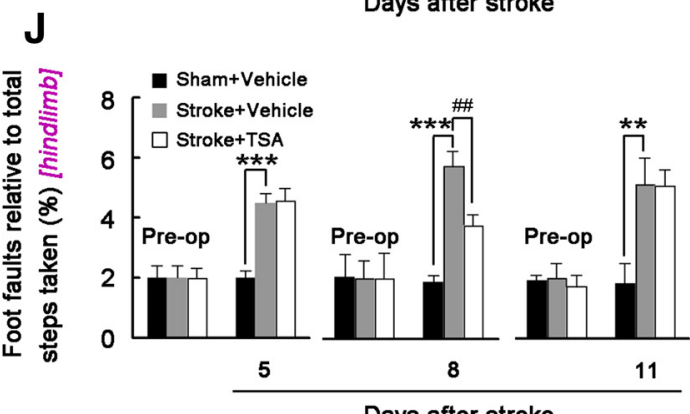

Days after stroke

K

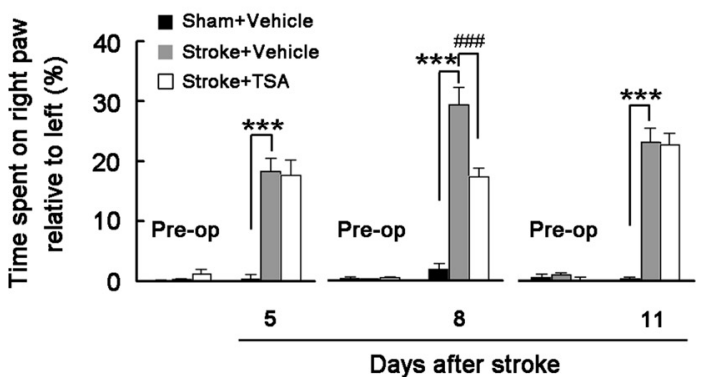

Figure 1. Time course of motor function after stroke and a window phase that TSA rescues secondary functional loss after stroke. $A$, Time course of motor function changes after stroke ( $n=13)$. ${ }^{*} p<0.05$ versus $3 \mathrm{~d}$ (two-tailed $t$ test). ${ }^{* * *} p<0.001$ versus $3 \mathrm{~d}$ (two-tailed $t$ test). ${ }^{\# \#} p<0.01$ versus $1 \mathrm{~d}$ (two-tailed $t$ test). ${ }^{\# \# \#} p<0.001$ versus $1 \mathrm{~d}$ (two-tailed $t$ test). $B$, Diagram defining the peri-infarct cortex for immunoblots. $C$, Representative immunoblots and bar graph showing the time course of acetyl-H4 levels in the peri-infarct cortex after stroke $\left(n=3, F_{(4,10)}=17.94\right) .{ }^{*} p=$ 0.02 at $3 \mathrm{~d}$ versus sham (ANOVA). ${ }^{* *} p<0.001$ at $6 \mathrm{~d}$ versus sham (ANOVA). ${ }^{* *} p=0.002$ at $9 \mathrm{~d}$ versus sham (ANOVA). ${ }^{* *} p=0.00412 \mathrm{~d}$ versus sham (ANOVA). D, Representative immunoblots and bar graph showing the time course of HDAC2 levels in the peri-infarct cortex after stroke $\left(n=3, F_{(4,10)}=5.54\right) .{ }^{*} p=0.015$ at $6 \mathrm{~d}$ versus sham (ANOVA). E, Time course of HDAC2 activity changes after stroke $\left(n=4, F_{(4,15)}=4.51\right) .{ }^{*} p=0.023$ at $6 \mathrm{~d}$ versus sham (ANOVA). $\boldsymbol{F}$, Representative immunoblots and bar graph showing the time course of HDAC3 levels in the peri-infarct cortex after stroke $\left(n=4\right.$, ANOVA, $\left.F_{(4,15)}=0.91\right)$. G, Diagram showing the microinjection of TSA via an implanted microcannula into the peri-infarct cortex of conscious mice for $\boldsymbol{H}-\boldsymbol{K}$. TSA $(0.5 \mu \mathrm{m} / 2 \mu \mathrm{l} / \mathrm{d})$ or vehicle was given $2-4,5-7$, or $8-10 \mathrm{~d}$ after stroke, and motor function was measured at $24 \mathrm{~h}$ after the last microinjection ( $n=10$ for sham, $n=13 \mathrm{for}$ others). $\boldsymbol{H}$, Representative immunoblots and bar graph showing acetyl-H4 level in the peri-infarct cortex. TSA $(0.5 \mu \mathrm{m} / 2 \mu \mathrm{l} / \mathrm{d})$ or vehicle was microinjected into the peri-infarct cortex 2-4,5-7, or $8-10 \mathrm{~d}$ after stroke, and Western blots were performed at $24 \mathrm{~h}$ after the last TSA infusion. TSA was given $2-4 \mathrm{~d}, n=4 .{ }^{*} p=0.014$ (two-tailed $t$ test). TSA was given $5-7 \mathrm{~d}, n=5$. ${ }^{*} p=0.017$ (two-tailed $t$ test). TSA was given $8-10 \mathrm{~d}, n=3 .{ }^{*} p=0.046$ (two-tailed $t$ test). $I$, Foot faults of left forelimb in the grid-walking task. For $5 \mathrm{~d}, F_{(2,33)}=39.16$. ${ }^{* * *} p<0.001$ (ANOVA). For $8 \mathrm{~d}, F_{(2,33)}=50.81$. ${ }^{* * *} p<0.001$ (ANOVA).

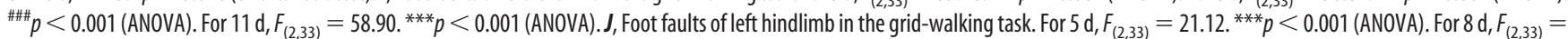
21.49. ${ }^{* * *} p<0.001$ (ANOVA). ${ }^{\# \#} p=0.005$ (ANOVA). For $11 \mathrm{~d}, F_{(2,33)}=9.52 .{ }^{* *} p=0.002$ (ANOVA). $K$, Forelimb symmetry in the cylinder task. For $5 \mathrm{~d}, F_{(2,33)}=22.32 .{ }^{* * *} p<0.001$ (ANOVA). For $8 \mathrm{~d}, F_{(2,33)}=49.13$. ${ }^{* * *} p<0.001$ (ANOVA). ${ }^{\# \#} p<0.001$ (ANOVA). For $11 \mathrm{~d}, F_{(2,33)}=56.54 .{ }^{* * *} p<0.001$ (ANOVA). Pre-op, Preoperation. 
A

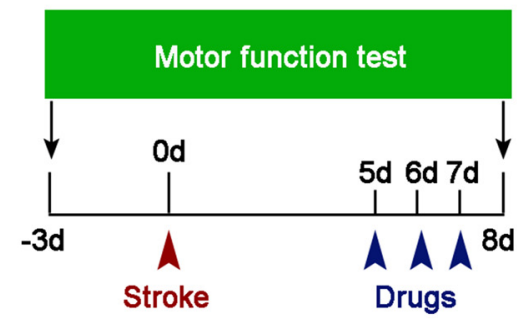

B

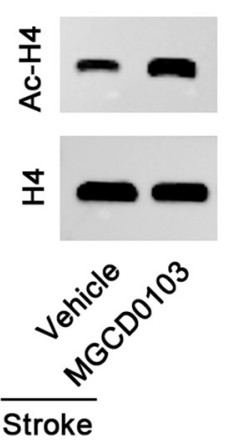

C
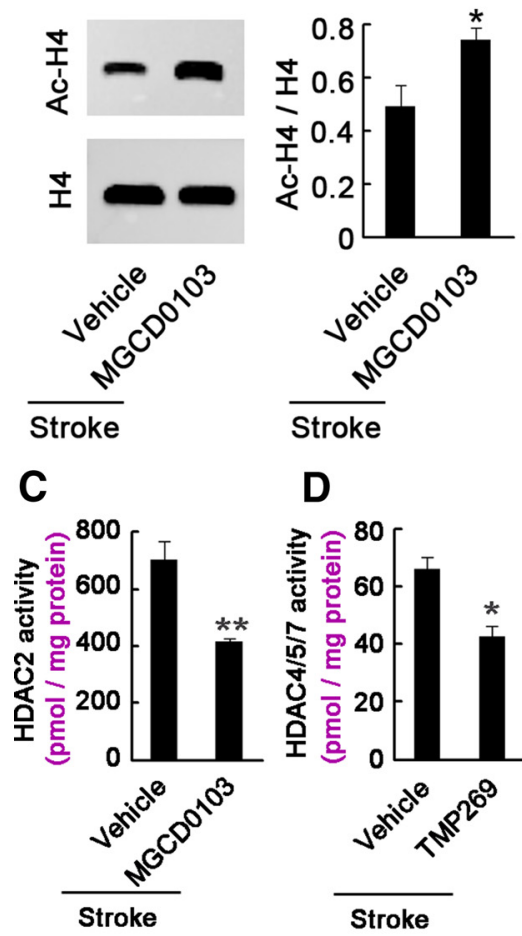

D

E

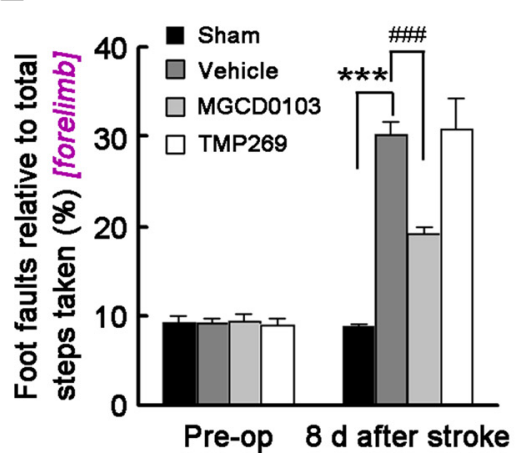

F

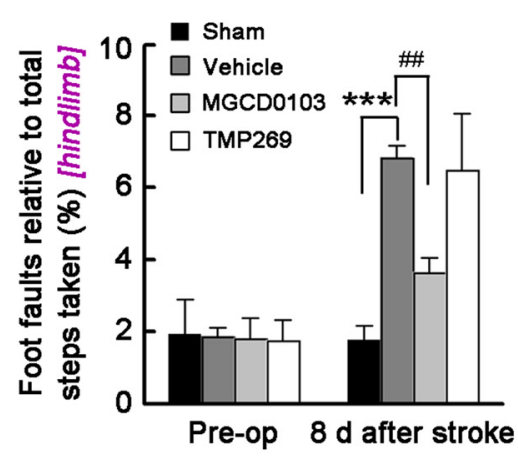

G

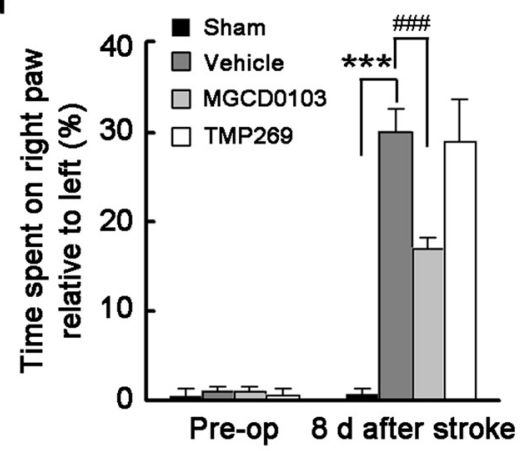

H

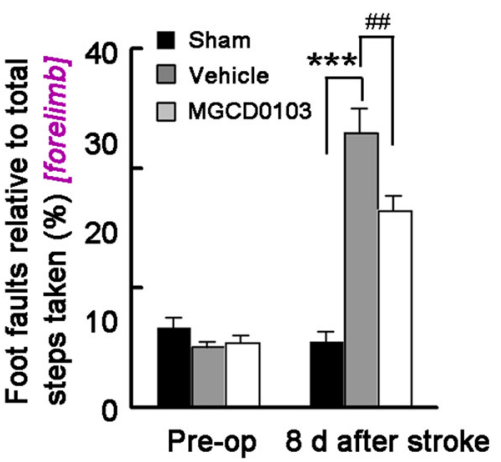

I

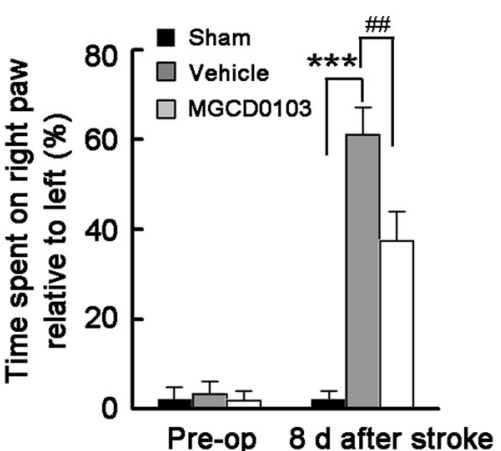

J
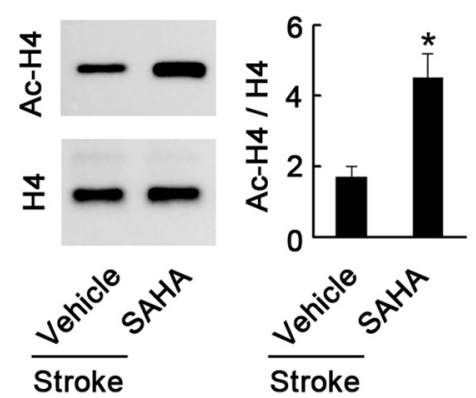

K

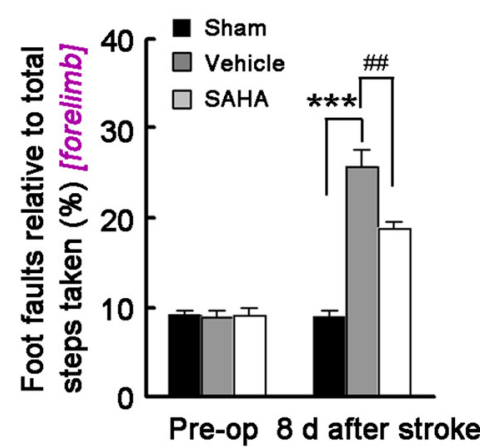

L

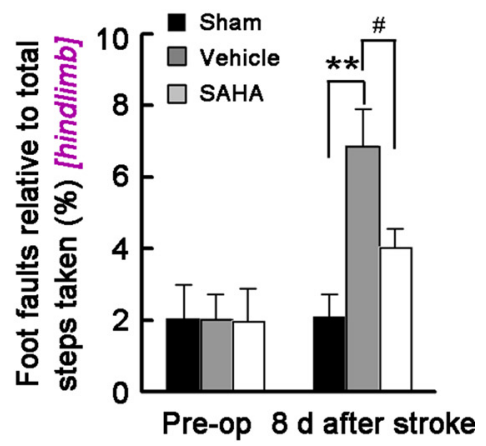

M

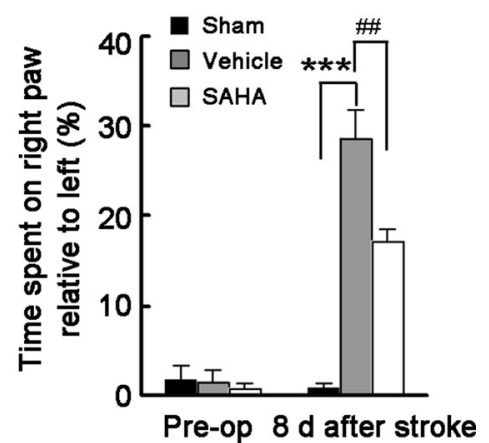

Figure 2. Class I, but not Class II, HDACs contribute to the regulation of functional recovery from stroke. $A$, Diagram showing the design of the experiments in $B-M$. MGCD0103 (1 $\mu \mathrm{M} / 2 \mu \mathrm{l} / \mathrm{d})$ or TMP269 $(10 \mu \mathrm{m} / 2 \mu \mathrm{l} / \mathrm{d}$ ) was infused into the peri-infarct cortex of mice $5-7 \mathrm{~d}$, and motor function was measured at $8 \mathrm{~d}$ after stroke ( $n=10$ for sham, $n=13 \mathrm{for}$ others). $\boldsymbol{B}$, Representative immunoblots and bar graph showing acetyl-H4 level in the peri-infarct cortex after MGCD0103 treatment. MGCD0103 or vehicle was microinjected into the peri-infarct cortex during 5-7 $d$, and immunoblots were performed $8 \mathrm{~d}$ after stroke $(n=5) .{ }^{*} p=0.026$ (two-tailed $t$ test). C, Activity of HDAC2 in the peri-infarct cortex at $24 \mathrm{~h}$ after the last MGCD0103 infusion ( $\left.n=4\right)$. ${ }^{* *} p=0.003$ (two-tailed $t$ test). D, Activity of HDAC4, HDAC5, and HDAC7 in the peri-infarct cortex at $24 \mathrm{~h}$ after the last TMP269 infusion $(n=3){ }^{*} p=0.011$ (two-tailed $t$ test). $E$, Foot faults of left forelimb in the grid-walking task $\left(F_{(3,45)}=35.55\right)$. ${ }^{* *} p<0.001$ (ANOVA). ${ }^{\# \# \#} p<0.001$ (ANOVA). $\boldsymbol{F}$, Foot faults of left hindlimb in the grid-walking task $\left(F_{(3,45)}=12.92\right)$. ${ }^{* * *} p<0.001$ (ANOVA). ${ }^{\# \#} p=$

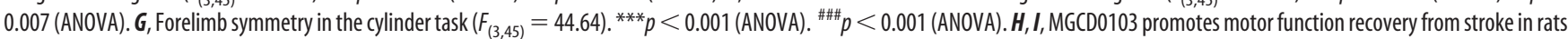
subjected to MCAO. MGCD0103 was given (10 mg/kg/d, i.p.) $5-7 \mathrm{~d}$, and motor function was measured at $8 \mathrm{~d}$ after stroke $(n=10$ for sham, $n=13 \mathrm{for}$ others). $\boldsymbol{H}$, Foot faults of left forelimb in the grid-walking task $\left(F_{(2,33)}=33.94\right) .{ }^{* * *} p<0.001$ (ANOVA). ${ }^{\# \#} p=0.001$ (ANOVA). $I$, Forelimb symmetry in the cylinder task (ANOVA, $\left.F_{(2,33)}=26.86\right) .{ }^{* * *} p 0.001$ (ANOVA). ${ }^{\#} p=0.025$ (ANOVA).J-M, Treatment with SAHA 5-7 d after stroke significantly improves motor function in mice. SAHA (10 $\mu \mathrm{m} / 2 \mu \mathrm{l} / \mathrm{d}$ ) was microinjected into the peri-infarct cortex $5-7 \mathrm{~d}$, and motor function was measured at $8 \mathrm{~d}$ after stroke ( $n=10$ for sham, $n=13$ for others). J, Representative immunoblots and bar graph showing that SAHA significantly increased acetyl-H4 level in the peri-infarct cortex. SAHA $(10 \mu \mathrm{m} / 2 \mu \mathrm{l} / \mathrm{d})$ or vehicle was microinjected into the peri-infarct cortex during 5-7 d, and immunoblots were performed $8 \mathrm{~d}$ after stroke (Figure legend continues.) 
A

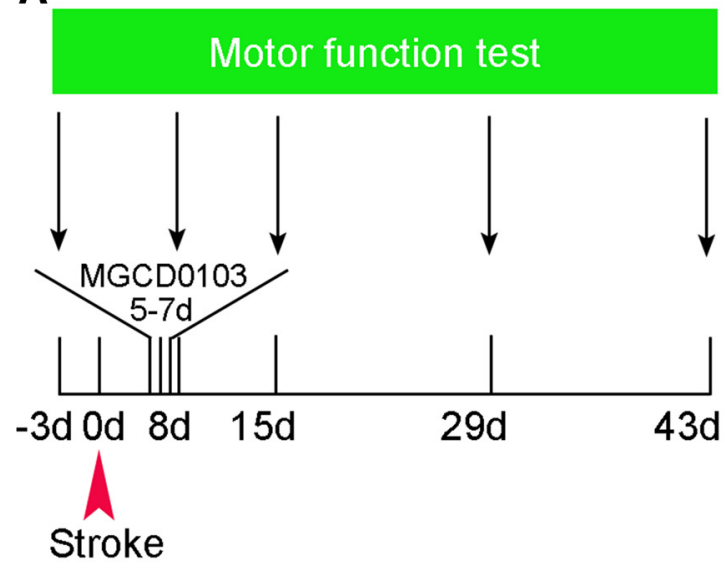

B

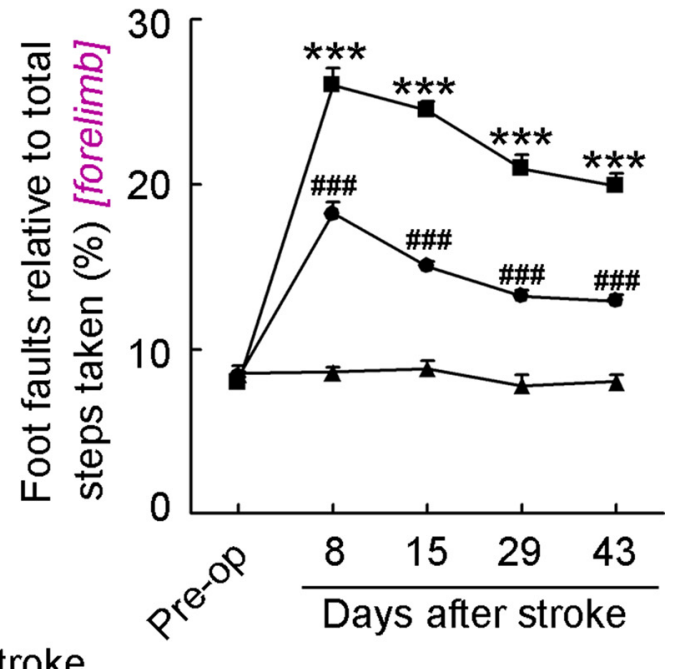

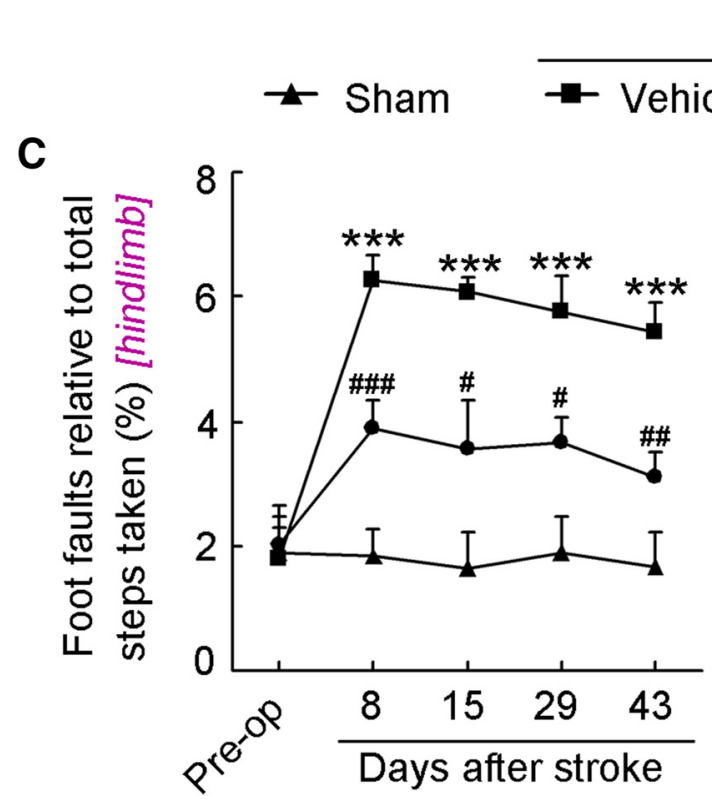

Stroke

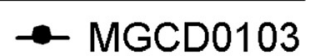

D

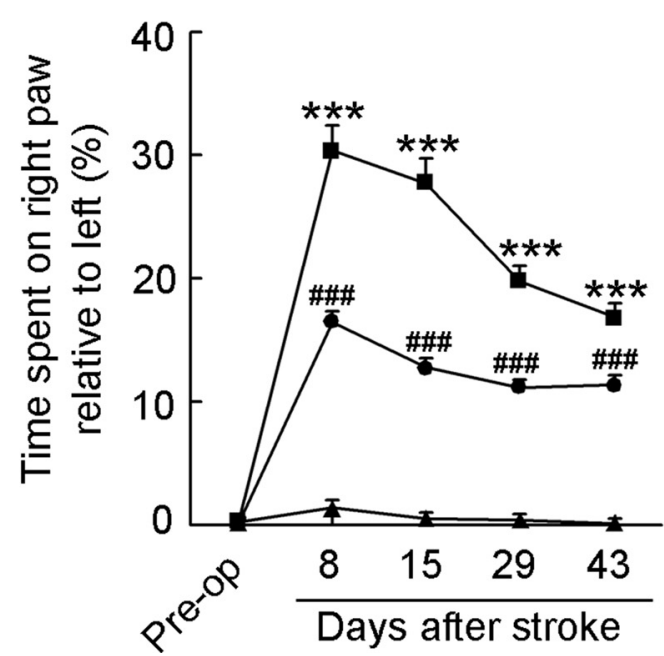

Figure 3. Inhibiting Class I HDACs produces a sustained functional recovery effect from stroke. $\boldsymbol{A}$, Experimental design for $\boldsymbol{B}-\boldsymbol{D}$. MGCD0103 $(1 \mu \mathrm{m} / 2 \mu \mathrm{l} / \mathrm{d})$ was microinjected into the peri-infarct cortex of mice during $5-7 \mathrm{~d}$ after stroke. $n=10$ for sham, $n=13$ for others. $\boldsymbol{B}$, Foot faults of left forelimb in the grid-walking task. ${ }^{* * *} p<0.001$ versus sham (ANOVA). ${ }^{\# \#} p<0.001$ versus vehicle (ANOVA). C, Foot faults of left hindlimb in the grid-walking task. ${ }^{* * *} p<0.001$ versus sham (ANOVA). ${ }^{\#} p<0.05$ versus vehicle (ANOVA). ${ }^{\# \#} p<0.01$ versus vehicle (ANOVA). ${ }^{\# \#} p<0.001$ versus vehicle (ANOVA). D, Forelimb symmetry in the cylinder task. ${ }^{* * *} p<0.001$ versus sham (ANOVA). ${ }^{\# \#} p<0.001$ versus vehicle (ANOVA). Pre-op, Preoperation.

was made for a leak component by linear extrapolation of the closed level below the threshold for activation of the voltage-gated current. All experiments were performed in a blind fashion.

Statistical analyses. All data are expressed as mean \pm SEM. Comparisons among multiple groups were made with one-way ANOVA (one factor) followed by Scheffé post hoc test. Comparisons between two groups were made with a two-tailed Student's $t$ test. Statistical significance was set at $p<0.05$. The sample size was predetermined by analyzing preexperimental data with PASS (power analysis and sample size) software. For animal studies, the sample size was predetermined by our prior experiment. Investigators were blind to treatment group when assessing the outcome.

$\leftarrow$

(Figure legend continued.) (vehicle, $n=6 ;$ SAHA, $n=5) .{ }^{*} p=0.036$ (two-tailed $t$ test). $\boldsymbol{K}$, Foot faults of left forelimb in the grid-walking task $\left(F_{(2,33)}=43.77\right)$. ${ }^{* * *} p<0.001$ (ANOVA). ${ }^{\# \#} p=$ 0.001 (ANOVA). $L$, Foot faults of left hindlimb in the grid-walking task $\left(F_{(2,33)}=9.81\right)$. ${ }^{* *} p=0.001$ (ANOVA). ${ }^{\#} p=0.032$ (ANOVA). $M$, Forelimb symmetry in the cylinder task $\left(F_{(2,33)}=40.01\right) .{ }^{* * *} p<0.001$ (ANOVA). ${ }^{\# \#} p=0.002$ (ANOVA). Pre-op, Preoperation.

\section{Results}

In this study, we produced a photothrombotic stroke in mice and daily detected motor function by measuring the number of foot faults in the grid-walking task and forelimb symmetry in the cylinder task (Clarkson et al., 2010) 1-14 d after stroke. Interestingly, a marked functional recovery occurred 2-4 d compared with $1 \mathrm{~d}$; motor function impairment was again exacerbated 5-7 d compared with $3 \mathrm{~d}$ and gradually improved from $8 \mathrm{~d}$ after stroke (Fig. 1A), indicating a typical secondary functional loss phase from 5 to $7 \mathrm{~d}$ after stroke. Ischemia caused a substantial decrease in histone acetylation in the peri-infarct cortex of mice during 3-12 d after photothrombotic stroke (Fig. 1B,C). Furthermore, expression and activity of HDAC2 were significantly upregulated at $6 \mathrm{~d}$ after stroke (Fig. 1D,E), whereas the protein level of HDAC3, a subtype of Class I HDACs mediating neuronal cell death in several neurodegenerative conditions (Yang and Seto, 2008), was unchanged in the delayed phase after stroke (Fig. $1 F$ ). Thus, HDACs may contribute to the secondary functional loss after stroke. 
A AAV-CAG-EGFP-Cre

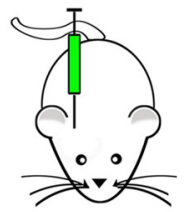

HDAC2 $2^{\text {flox/flox }}$ mouse
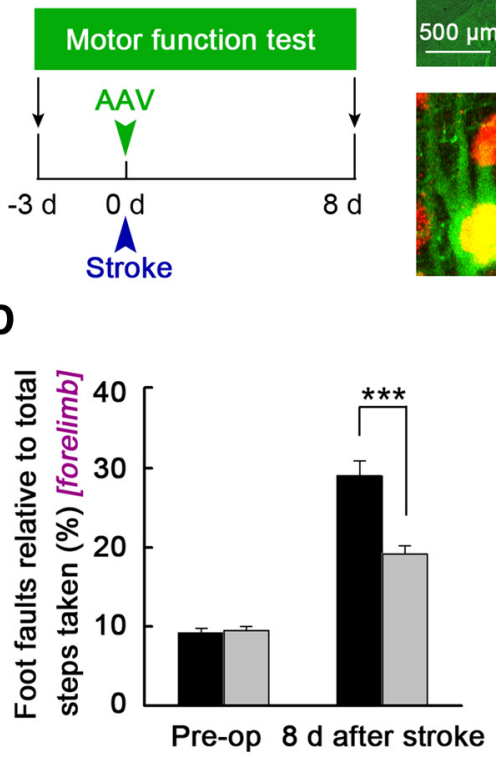

B
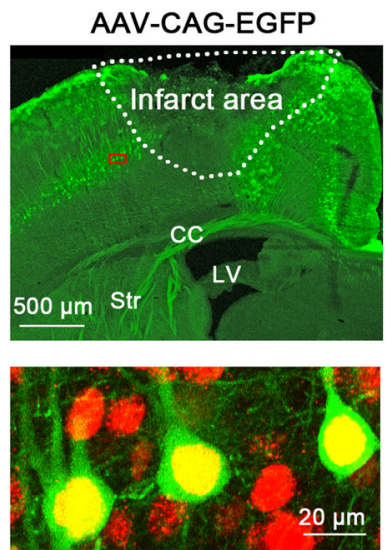

C
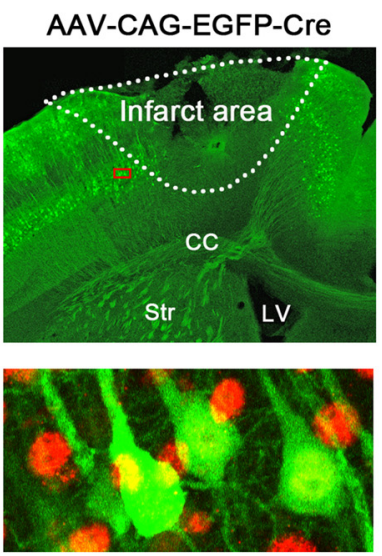
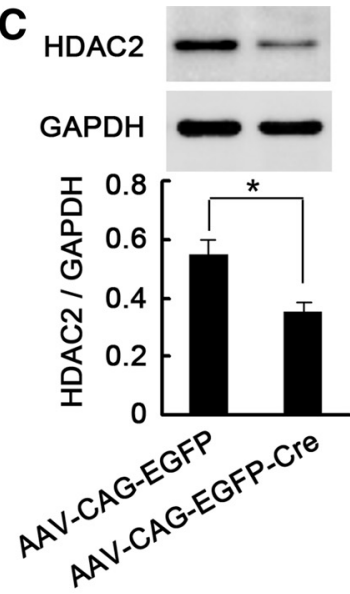

D

E

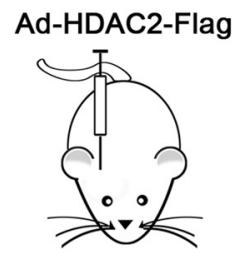

F

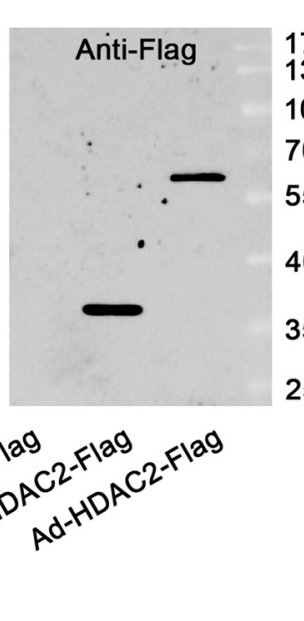

AAV-CAG-EGFP

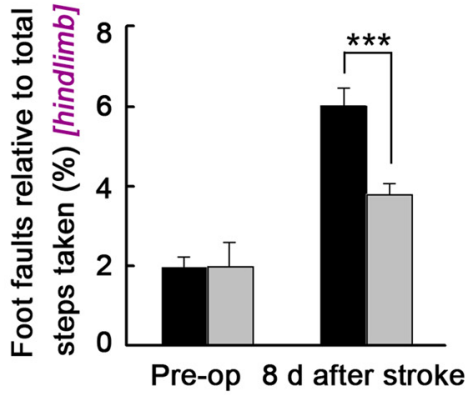

170
130
100
70
55
40
35
25

G

$$
\text { GA }
$$

HDAC2

GAPDH

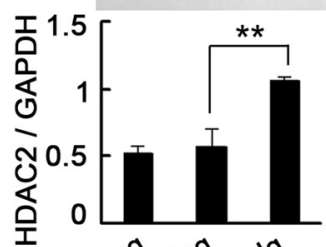

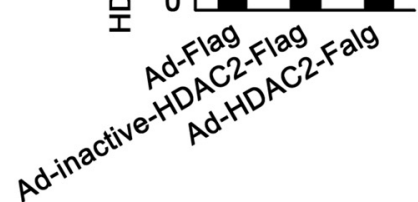

H

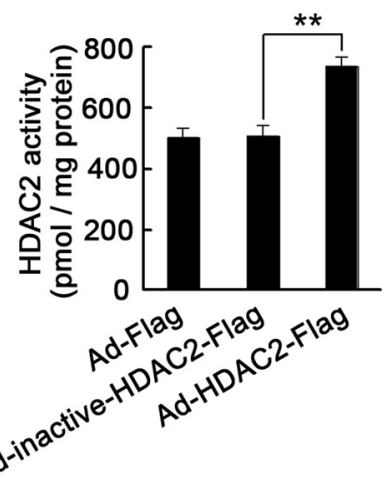

I

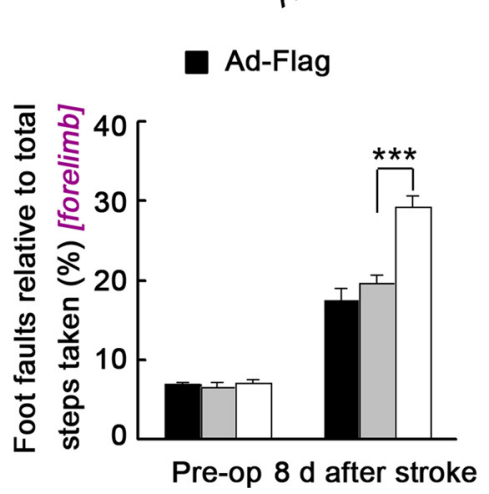

Ad-inactive-HDAC2-Flag

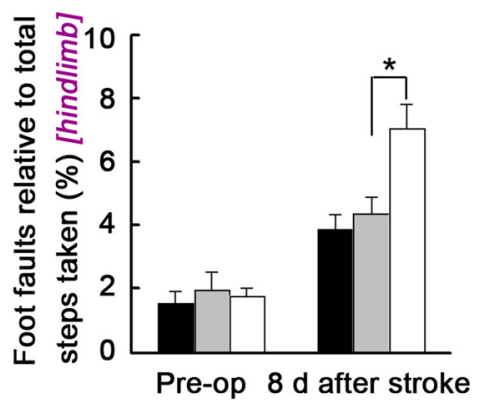

Ad-HDAC2-Flag

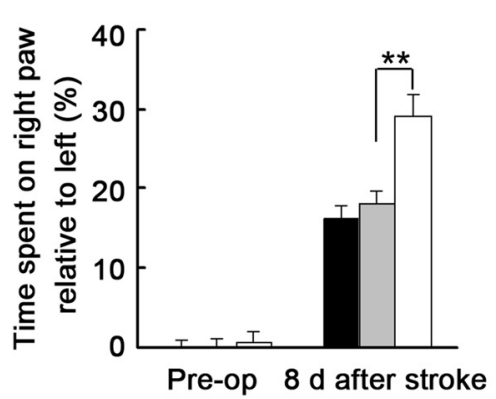

Figure 4. HDAC2 mediates secondary functional loss after stroke. $A$, Diagram showing the infusion of AAV-CAG-EGFP-Cre or its control into the peri-infarct cortex of HDAC2 ${ }^{\text {floxfflox }}$ mice and experimental design for $\boldsymbol{B}-\boldsymbol{D}$. $\boldsymbol{B}$, Representative images showing AAV-infected the peri-infarct cortex (top) at $5 \mathrm{~d}$ after stroke and high-magnification images from selected area in the top images that were stained with EGFP and HDAC2. CC, Corpus callosum; Str, striatum; LV, lateral ventricle. C, Representative immunoblots and histogram showing HDAC2 levels in AAV-CAG-EGFP-Cre- or AAV-CAG-EGFP-infected peri-infarct cortex $5 \mathrm{~d}$ after stroke $\left(n=4,{ }^{*} p=0.014\right.$, two-tailed $t$ test). $D$, Foot faults of left forelimb (left, ${ }^{* * *} p<0.001$ ) and of left hindlimb (Figure legend continues.) 
To investigate the role of HDACs in the secondary functional loss phase, we infused a pan-HDAC inhibitor TSA daily into the peri-infarct cortex of conscious mice via an implanted microcannula (Fig. 1G) 2-4, 5-7, or 8-10 d after stroke and tested motor function at $3 \mathrm{~d}$ before stroke and $24 \mathrm{~h}$ after the last TSA injection. These TSA treatments significantly increased acetyl-H4 level in the peri-infarct cortex, compared with vehicle (Fig. $1 H$ ). Surprisingly, treatment with TSA $5-7 \mathrm{~d}$, but not $2-4$ or $8-10 \mathrm{~d}$, after stroke significantly ameliorated ischemia-induced motor function impairment (Fig. $1 I-K$ ), suggesting that HDACs play a critical role in the secondary functional loss phase.

HDACs have been divided into Classes I (HDAC 1-3, 8), II (HDAC 4-7, 9, and 10), III (sirtuins), and IV (HDAC 11) (Krämer, 2009). To examine effects of class-specific HDACs inhibitors on stroke recovery, we daily infused MGCD0103, a selective inhibitor of the Class I HDACs, including HDAC1, HDAC2, HDAC3 (Cavasin et al., 2012), and TMP269, a selective inhibitor of the Class IIa HDACs, including HDAC4, HDAC5, HDAC7, and HDAC9 (Lobera et al., 2013), into the peri-infarct cortex of conscious mice 5-7 $\mathrm{d}$ and measured motor function at $8 \mathrm{~d}$ after stroke. MGCD0103 inhibited HDAC2 activity (Fig. $2 A-C)$ and ameliorated ischemia-induced functional impairment (Fig. 2E-G). TMP269 significantly increased acetyl-H4 level (acetyl-H4/H4: $0.42 \pm 0.01$ vs $0.88 \pm 0.11 ; n=4 ; p=0.008$ ) and inhibited the activity of HDAC4/5/7 (Fig. 2D), but did not affect motor function (Fig. 2E-G), compared with vehicle. TMP269 had no effect on HDAC2 activity (743.18 \pm 37.09 $\mathrm{pmol} / \mathrm{mg}$ protein vs $738.60 \pm 73.00 \mathrm{pmol} / \mathrm{mg}$ protein; $n=4 ; p=$ 0.96). Moreover, treatment with MGCD0103 5-7 d after stroke $(10 \mathrm{mg} / \mathrm{kg} / \mathrm{d}$, i.p.) significantly improved motor function of the rats subjected to transient MCAO for $120 \mathrm{~min}$ (Fig. $2 \mathrm{H}, \mathrm{I}$ ). Thus, the Class I, but not Class II, HDACs mediate the secondary functional loss after stroke. Furthermore, administration of SAHA, a selective inhibitor of HDAC1, HDAC2 (Salisbury and Cravatt, 2007), which has been approved by FDA to treat cancer, 5-7 d after stroke promoted functional recovery from stroke to a similar extent as that observed in the stroke mice treated with MGCD0103 (Fig. 2J-M). All these data suggest that HDAC1 and HDAC2 contribute to the secondary functional loss after stroke. HDAC2 is an isoform negatively regulating cell survival (Nott et al., 2008) and neuronal plasticity (Gräff et al., 2014). In contrast, HDAC1 gain of function has a potent protection effect against neurotoxicity in vivo model for ischemia (Kim et al., 2008). Furthermore, we evaluated the motor function over a time course and found that MGCD0103-treated mice displayed significantly

\footnotetext{
$\leftarrow$

(Figure legend continued.) (middle, ${ }^{* * *} p<0.001$ ) in the grid-walking task and forelimb symmetry in the cylinder task (right, $\left.{ }^{*} p=0.014\right)(n=10$, two-tailed $t$ test). $\boldsymbol{E}$, Diagram showing the infusion of Ad-HDAC2-Flag or its control into the peri-infarct cortex of mice and experimental design for $\boldsymbol{F}-\boldsymbol{I}$. $\boldsymbol{F}-\boldsymbol{H}$, Confirmation of Ad-Flag, Ad-inactive-HDAC2-Flag, and Ad-HDAC2Flag. $\boldsymbol{F}$, Representative gel showing inactive-HDAC2-Flag and HDAC2-Flag expression in the peri-infarct cortex of mice at $5 \mathrm{~d}$ after Ad-inactive-HDAC2-Flag or Ad-HDAC2-Flag infection. G, HDAC2 levels in the peri-infarct cortex at $5 \mathrm{~d}$ after Ad-Flag, Ad-inactive-HDAC2-Flag, or Ad-HDAC2-Flag infection $\left(n=4, F_{(2,9)}=13.82\right) .{ }^{* *} p=0.006$ (ANOVA). $\boldsymbol{H}$, Activity of HDAC2 in the peri-infarct cortex at $5 \mathrm{~d}$ after Ad-Flag, Ad-inactive-HDAC2-Flag, or Ad-HDAC2-Flag infection $\left(n=4, F_{(2,9)}=17.95\right) .{ }^{* *} p=0.002$ (ANOVA). I, Overexpression of HDAC2 worsens functional impairment after stroke. Stroke was induced by illumination with cold light source for $10 \mathrm{~min}$, different from other experiments with illumination for $15 \mathrm{~min}$. Ad-Flag, Ad-HDAC2Flag, or Ad-inactive-HDAC2-Flag was infused into the peri-infarct cortex immediately after stroke. Foot faults of left forelimb (left, $F_{(2,27)}=23.19,{ }^{* * *} p<0.001$ ) and of left hindlimb (middle, $F_{(2,27)}=8.62,{ }^{*} p=0.011$ ) in the grid-walking task and forelimb symmetry in the cylinder task (right, $\left.F_{(2,27)}=12.01,{ }^{* *} p=0.003\right)$ were measured at the time indicated $(n=$ 10, ANOVA). Pre-op, Preoperation.
}

better motor function than vehicle-treated mice did during 8-43 $\mathrm{d}$ after stroke, indicating an early and sustained functional recovery (Fig. 3). Collectively, HDAC2 may be a key mediator for the secondary functional loss after stroke.

To address this, we infused adeno-associated virus vector AAV-CAG-EGFP-Cre into the peri-infarct cortex of HDAC2 flox/flox mice immediately after photothrombotic stroke (Fig. $4 A$ ) and found that this treatment deleted HDAC2 in the infected cells (Fig. 4B), substantially reduced HDAC2 level in the peri-infarct cortex, and significantly improved motor function at $8 \mathrm{~d}$ after stroke (Fig. 4C,D). Moreover, we generated an adenovirus vector selectively expressing HDAC2 (Ad-HDAC2-Flag), its control an adenovirus vector only or an adenovirus vector expressing inactive HDAC2 (Ad-inactive-HDAC2-Flag), and infused them into the peri-infarct cortex of mice immediately after stroke and measured motor function at $8 \mathrm{~d}$ after stroke (Fig. $4 E$ ). Ad-HDAC2Flag substantially increased HDAC2 level and activity $5 \mathrm{~d}$ after stroke (Fig. $4 F-H$ ) and worsened the stroke-induced functional impairment $8 \mathrm{~d}$ after stroke (Fig. 4I). Thus, HDAC2 in the periinfarct cortex plays a critical role for the secondary functional loss after stroke.

To determine whether HDAC2 is a unique target for the effect of HDACs inhibitors on stroke recovery and avoid the developmental abnormality that occurs following deletion of Hdac2 during development (Guan et al., 2009), Hdac2 CKO mice were generated by crossing HDAC2 $2^{\text {flox/flox }}$ mice with EMX1-Cre transgenic mice. EMX1 is expressed exclusively in the dorsal telencephalon from embryonic stages to adulthood (Iwasato et al., 2000). Hdac2 CKO mice (HDAC2 $2^{\text {flox/flox }}$-EMX1-Cre) had normal brain anatomy (data not shown) and body weight $(23.19 \pm 0.301$ g vs $23.25 \pm 0.220 \mathrm{~g} ; n=15 ; p=0.873$ ) compared with WT $\left(\mathrm{HDAC}^{\text {flox/flox }}\right)$ littermates. Immunofluorescence showed that HDAC2 was deleted in the vast majority of nerve cells (Fig. $5 A$ ), and Western blotting showed that HDAC2 level was reduced by $\sim 90 \%$ in the peri-infarct cortex of Hdac2 CKO mice (Fig. 5B). Next, we infused TSA daily into the peri-infarct cortex of conscious Hdac2 CKO mice and WT littermates 5-7 d after stroke, and tested motor function at $8 \mathrm{~d}$ after stroke. Compared with WT mice, $H d a c 2$ CKO mice displayed significantly decreased number of foot faults and improved forelimb symmetry, further suggesting that HDAC2 loss of function enhanced motor function recovery from stroke. Importantly, treatment with TSA was ineffective in Hdac2 CKO mice, although the drug significantly ameliorated stroke-induced functional impairment in WT mice (Fig. 5C). Moreover, we infused Ad-HDAC2-Flag or its control Ad-inactive-HDAC2-Flag into the peri-infarct cortex of Hdac2 CKO mice immediately and measured motor function at $8 \mathrm{~d}$ after stroke. Ad-HDAC2-Flag significantly worsened the strokeinduced functional impairment $8 \mathrm{~d}$ after stroke but had no effect on sham-operated mice, suggesting that the functional rescue effect of Hdac2 CKO mice is HDAC2 activity-dependent (Fig. 5D). Together, these findings support the notion that HDAC2, rather than other HDACs, contributes to the secondary functional loss after stroke.

Consistent with our previous results (Fig. $1 D, E$ ), we observed upregulation of HDAC2 in the peri-infarct area after stroke by immunofluorescence analyses (Fig. 6A,B). To know how ischemia upregulates HDAC2, we examined effects of free radicals and inflammatory factors, key pathophysiological mechanisms underlying secondary injury after stroke (Shichita et al., 2009; Walsh et al., 2014), on HDAC2 expression. We treated the cultured cortical neurons by $\mathrm{H}_{2} \mathrm{O}_{2}$ combined with peroxynitrite $\left(\mathrm{ONOO}^{-}\right)$or by inflammatory factors $\mathrm{TNF} \alpha$ combined with 
A
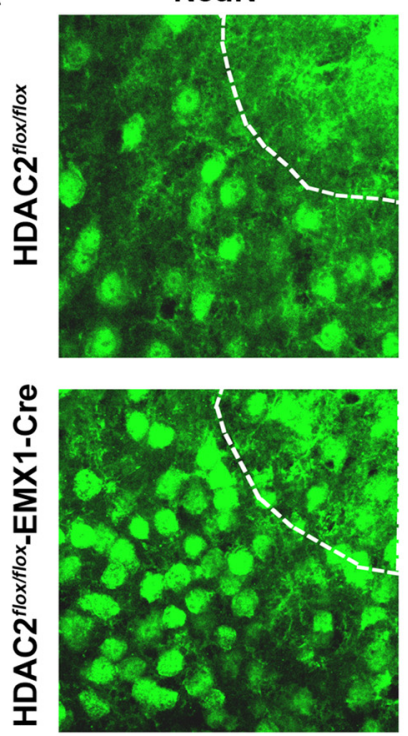

HDAC2
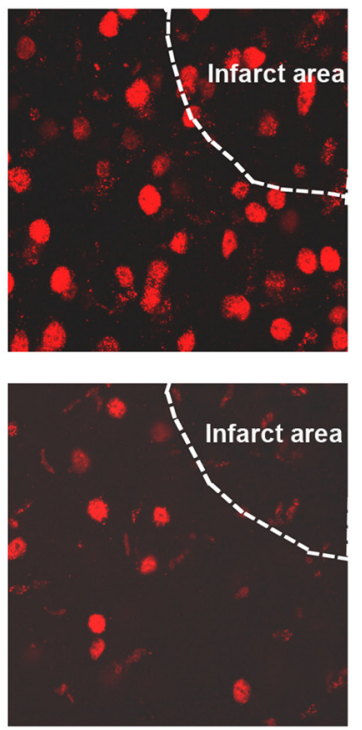

Merge
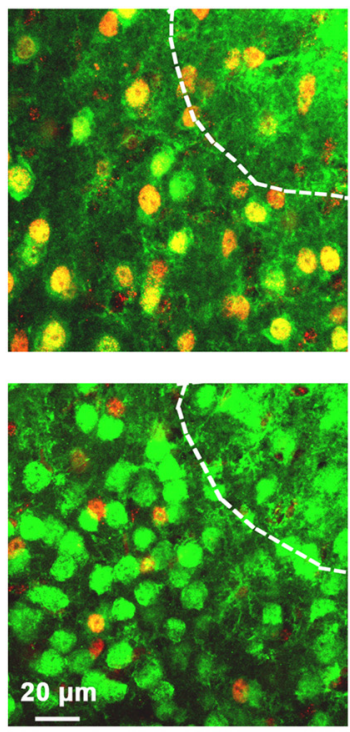

Stroke/vehicle $(n=9)$

Stroke/vehicle $(n=7)$
B
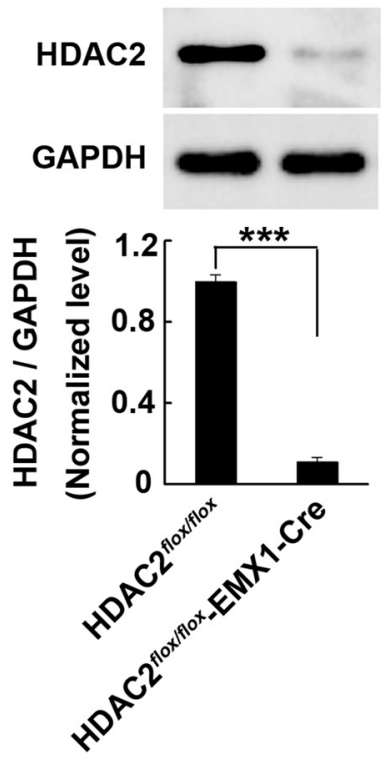

Stroke/TSA $(n=9)$

Stroke/TSA $(n=8)$

HDAC2 ${ }^{\text {flox/flox }}$-EMX1-Cre: $\square$ Sham/vehicle $(n=8)$

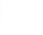
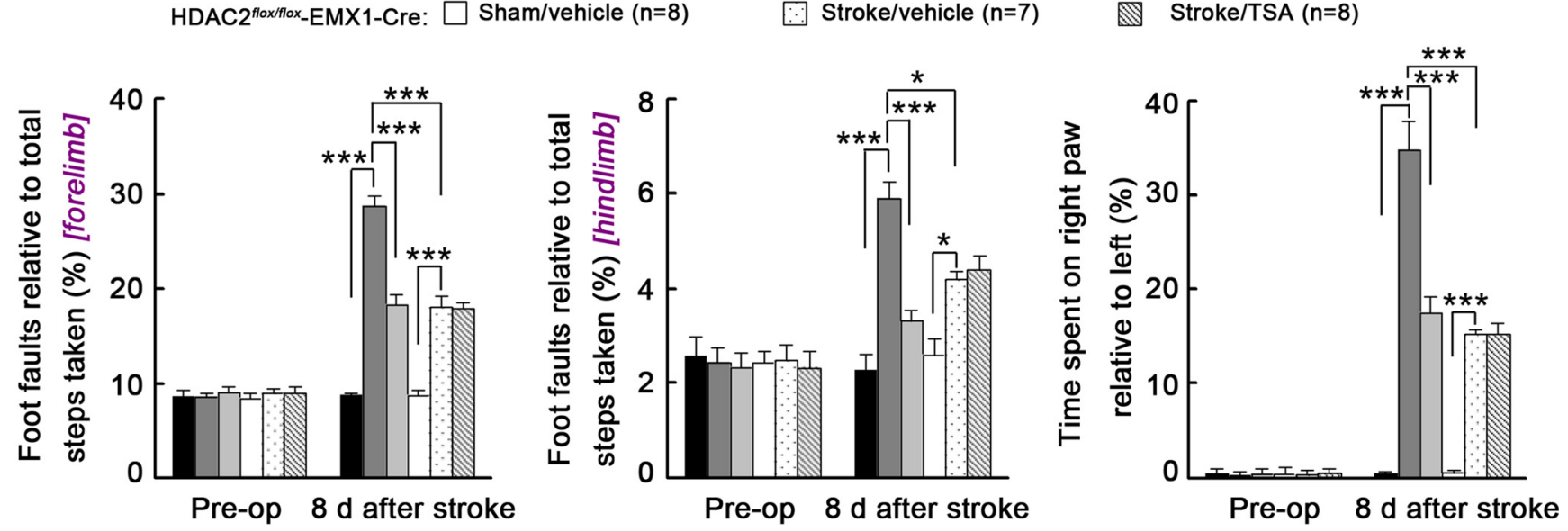

D

Sham

Stroke

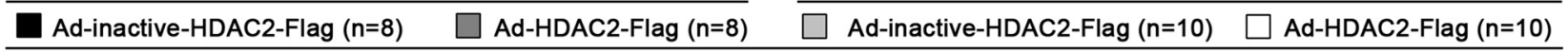
HDAC2 ${ }^{\text {floxfflox_EMX1-Cre }}$
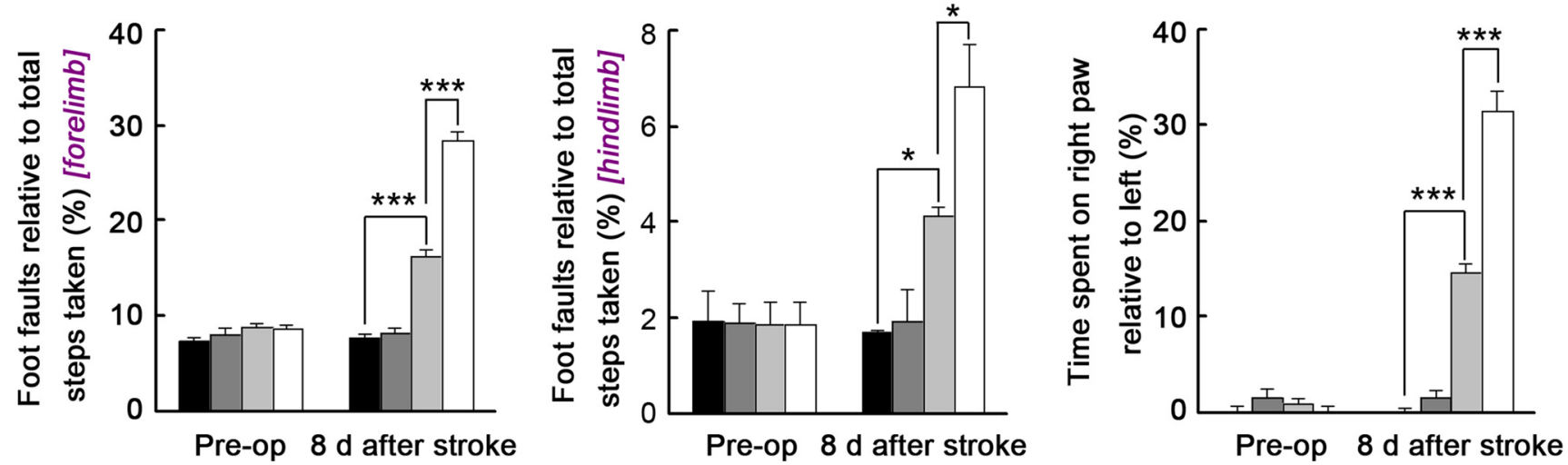

Figure 5. HDAC2 is the only target for functional recovery from stroke. $A$, Representative images showing the deletion of HDAC2 in the vast majority of nerve cells in the peri-infarct cortex of $H$ dac2 CKO mice at $8 \mathrm{~d}$ after stroke. Scale bar, $20 \mu \mathrm{m}$. B, Representative immunoblots and bar graph showing HDAC2 levels in the peri-infarct cortex of Hdac2 ${\text { CKO mice and of HDAC2 } 2^{f l o x} / f l o x}_{\text {littermates at }}$ $8 \mathrm{~d}$ after stroke. $n=4 .{ }^{* * *} p<0.001$ (two-tailed $t$ test). C, TSA significantly decreased functional impairments in HDAC2 ${ }^{\text {floxfflox }}$ littermates, as shown in foot faults of left forelimb (left, ANOVA, $F_{(5,44)}=94.90,{ }^{* * *} p<0.001$ ) and of left hindlimb (middle, ANOVA, $F_{(5,44)}=22.12,{ }^{*} p<0.05,{ }^{* * *} p<0.001$ ) in the grid-walking task, and forelimb symmetry in the cylinder task (right, ANOVA, $\left.F_{(5,44)}=63.18,{ }^{* * *} p<0.001\right)$, but was ineffective in Hdac2 CKO mice (ANOVA, $\left.p>0.05\right)$. TSA $(0.5 \mu \mathrm{m} / 2 \mu \mathrm{l} / \mathrm{d}$ ) was infused into the peri-infarct cortex $5-7 \mathrm{~d}$, and motor function was measured at $8 \mathrm{~d}$ after stroke. D, HDAC2 overexpression markedly worsened motor function of Hdac2 CKO mice after stroke, as shown in foot faults of (Figure legend continues.) 
IL- $1 \beta$ and MMP9, and found that they significantly increased HDAC2 expression (Fig. 6C-F). Although NMDA type of glutamate receptor (NMDAR) overactivation is crucial for neuronal death (Zhou et al., 2010), NMDA did not change HDAC2 expression in the cultured neurons (Fig. 6G). Thus, ischemia-induced production of free radicals and inflammatory factors may account for HDAC2 upregulation after stroke.

Although a variety of HDAC inhibitors, including pan- and classspecific HDAC inhibitors, when used before stroke, immediately or within hours after stroke, can protect against ischemic damage (Langley et al., 2009; Aune et al., 2015), showing neuroprotection in the very early phase of stroke, it remains unknown whether delayed administration of MGCD0103 after stroke promotes functional recovery via reducing infarct volume. To investigate this issue, we assessed stroke volume at $8 \mathrm{~d}$ after photothrombotic stroke in animals treated with vehicle or MGCD0103 during 5-7 d after stroke. Stroke volumes were similar between mice treated with vehicle and MGCD0103 $\left(0.80 \pm 0.09 \mathrm{~mm}^{3}\right.$ vs $0.78 \pm 0.12 \mathrm{~mm}^{3} ; n=8 ; p=$ 0.93 ), suggesting that MGCD0103 rescues secondary functional loss after stroke probably via other mechanisms rather than reducing infarct size.

To explore the mechanisms underlying HDAC inhibitorproduced functional rescue, we performed RNA sequencing of peri-infarct cortex extracts from both MGCD0103- and vehicletreated animals 5-7 d after stroke. At an expression fold change cutoff of 2.0, we found 1148 differentially expressed genes (DEGs) between MGCD0103- and vehicle-treated cortices, among which 417 genes showed higher expression and 731 genes showed lower expression (Fig. 7A). Unsupervised cluster analysis of these transcriptomes confirmed that the gene expression changes about vehicle-treated animals versus MGCD0103treated animals clustered together (Fig. $7 B$ ). Upon generation of pathway and gene ontology analyses, we noticed these DEGs between vehicle- and MGCD0103-treated cortex to be implicated in biological processes related to inflammatory response, superoxide anion generation, neuronal plasticity, and others (Fig. 7C).

Neuronal plasticity can lead to the remapping of function from damaged areas to peri-infarct surviving tissue (Murphy and Corbett, 2009; Li et al., 2015). We thus detected several key proteins of neuronal plasticity to be significantly changed in MGCD0103-treated cortex (Fig. 7B), including NOVA1, a regulator of neuronal miRNA function (Störchel et al., 2015), UNC5C, a netrin receptor (Wetzel-Smith et al., 2014), Bestrophin 1 (BEST1), an anion channel contributing to GABA tonic inhibition $\left(I_{\text {tonic }}\right)$ (Lee et al., 2010), and DISC1, a regulator of mitochondrial dynamics controlling the morphogenesis of neuronal dendrites and axons (Norkett et al., 2016). Immunoblotting analysis of independent MGCD0103- and vehicle-treated samples confirmed the expression changes (Fig. $7 D-F$ ). Furthermore, the genes with higher expression also showed higher acetylation in their promoter region (Fig. 7G). These findings suggest that neuroplasticity in the peri-infact area at the level of gene expression was enhanced when treated with MGCD0103.

Excitation-inhibition imbalance also plays an important role in mediating stroke recovery (Clarkson et al., 2010; Hiu et al., 2016). More importantly, RNA sequencing of peri-infarct cortex

\section{$\leftarrow$}

(Figure legend continued.) left forelimb (left, ANOVA, $F_{(3,32)}=243.73$, ${ }^{* * *} p<0.001$ ) and of left hindlimb (middle, ANOVA, $\left.F_{(3,32)}=17.92,{ }^{*} p<0.05\right)$ in the grid-walking task, and forelimb symmetry in the cylinder task (right, ANOVA, $F_{(3,32)}=131.47,{ }^{* * *} p<0.001$ ). Pre-op, Preoperation. extracts revealed that MGCD0103 reversed stroke-induced Best1 upregulation (Fig. $7 B$ ), which was further confirmed by Western blot analysis of the peri-infarct cortex tissue (Fig. 7D), implicating that Class I HDACs were involved in the regulation of GABAergic signaling. Accordingly, we collected interstitial fluid samples from peri-infarct cortex of different groups by microdialysis (Fig. 8A). LC-MS/MS analysis of the samples revealed that stroke led to significant increased levels of both extracellular glutamate and GABA, and treatment with MGCD0103 5-7 d after stroke reversed the ischemia-induced extracellular level of GABA but not of glutamate (Fig. $8 B, C$ ). Extracellular concentration of GABA is critical in determining tonic conductance and tonically active extrasynaptic $\mathrm{GABA}_{\mathrm{A}}$ receptors set an excitability threshold for neurons and control LTP (Clarkson et al., 2010). Therefore, we performed whole-cell voltage-clamp recordings in the peri-infarct cortex in in vitro brain slices prepared at $8 \mathrm{~d}$ after stroke. We found that a significant increase in $I_{\text {tonic }}$ in pyramidal neurons after stroke, consistent with previous findings (Clarkson et al., 2010), and more importantly, treatment with MGCD0103 5-7 d after stroke reversed the ischemia-induced $I_{\text {tonic }}$ (Fig. $8 D, E)$. Moreover, MGCD0103 did not affect phasic inhibitory currents (Fig. $8 F, G$ ), resting membrane and GABA reversal potentials (Fig. $8 H$ ). Thus, inhibiting Class I HDACs may enhance excitability in the peri-infarct cortex by regulating $I_{\text {tonic }}$. Reducing excessive GABA-mediated $I_{\text {tonic }}$ and enhancing excitability in surviving neurons promote functional recovery after stroke (Murphy and Corbett, 2009; Clarkson et al., 2010). Collectively, our findings suggest that inhibiting Class I HDACs enhances functional neuroplasticity of peri-infarct cortex after stroke.

Finally, we investigated the role of Class I HDACs in cell survival and neuroinflammation. We infused MGCD0103 into the peri-infarct cortex of conscious mice 5-7 d after stroke. Next day, we measured the number of surviving neurons and amoeboid microglia, an indicator of phagocytic activity (Neher et al., 2013), and important regulators of cell survival and neuroinflammation, including BDNF, TNF $\alpha$, and IL- $1 \beta$. As expected, treatment with MGCD0103 significantly increased the number of surviving neurons and BDNF level (Fig. 9A-C), and substantially decreased the number of amoeboid microglia (Fig. $9 A, D$ ), and reversed stroke-induced upregulation of TNF $\alpha$ and IL- $1 \beta$ in the periinfarct cortex (Fig. 9E, F). Thus, in addition to substantially increased neuroplasticity, inhibiting Class I HDACs may promote functional recovery after stroke via enhancing survival and alleviating neuroinflammation.

Additionally, the effect of HDAC interventions on motor function was specific to the injured cortex, as we did not detect obvious changes to the number of foot faults in right limbs in the grid-walking task between groups in all experiments (data not shown).

\section{Discussion}

This study demonstrates that inhibiting HDAC2 in the periinfarct area from 5 to $7 \mathrm{~d}$ after stroke rescues secondary functional loss, thereby opening a new window for the treatment of stroke. Specific pattern of distribution among cells and subcellular locations, and specific regulation of target genes may explain the unique role of HDAC2. Class I HDACs are generally restricted to the nucleus where they impose transcriptional control, Class IIa HDACs transit the nuclear membranes and enter the cytoplasmina process mediated by phosphorylation (Aune et al., 2015). In the ischemic penumbra, HDAC1 and HDAC3 are prominently expressed in proximal axons and dendrites of neu- 
A

A

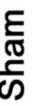
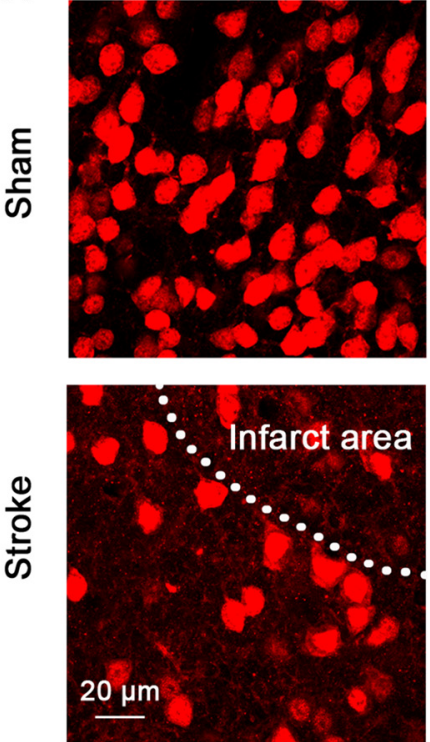

C
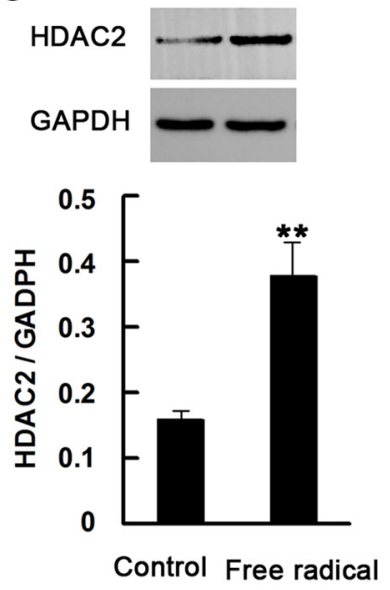

E

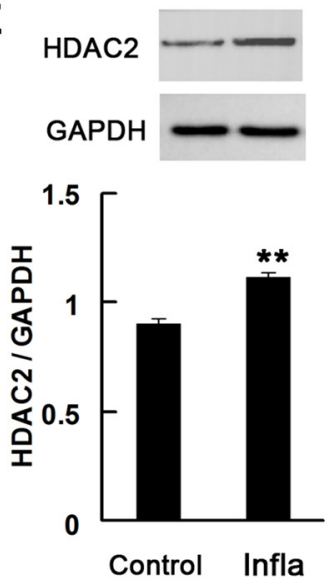

HDAC2
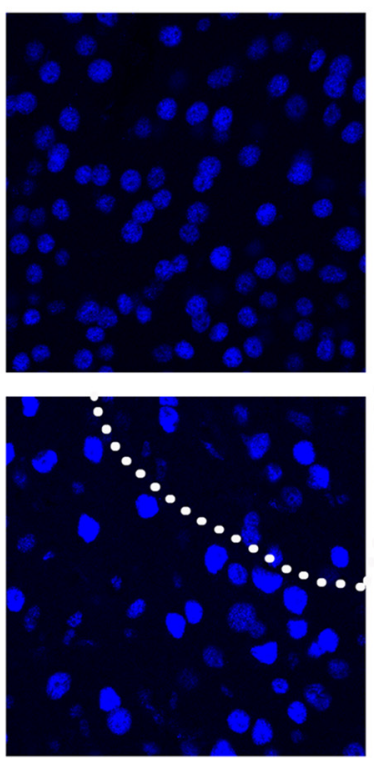

Merge
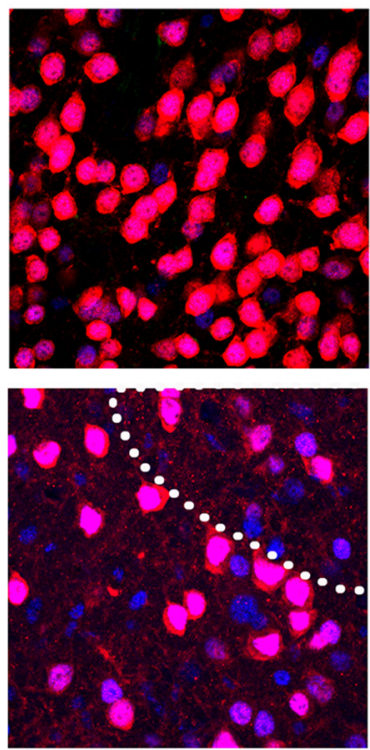

B

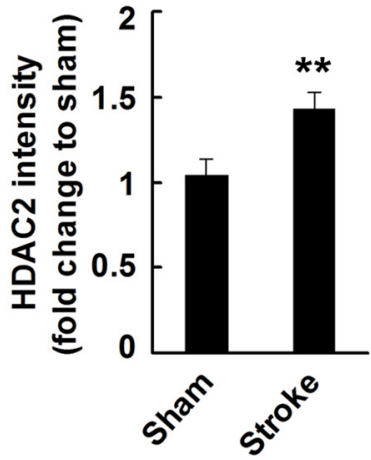

G
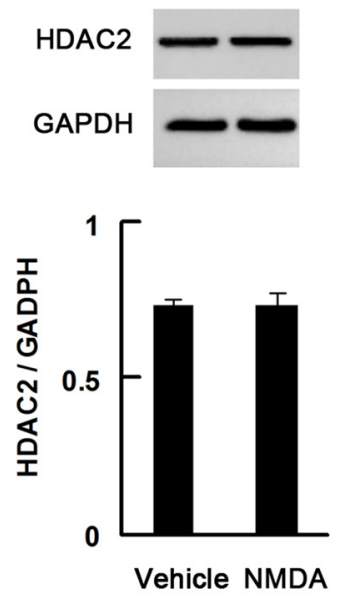

Vehicle NMDA
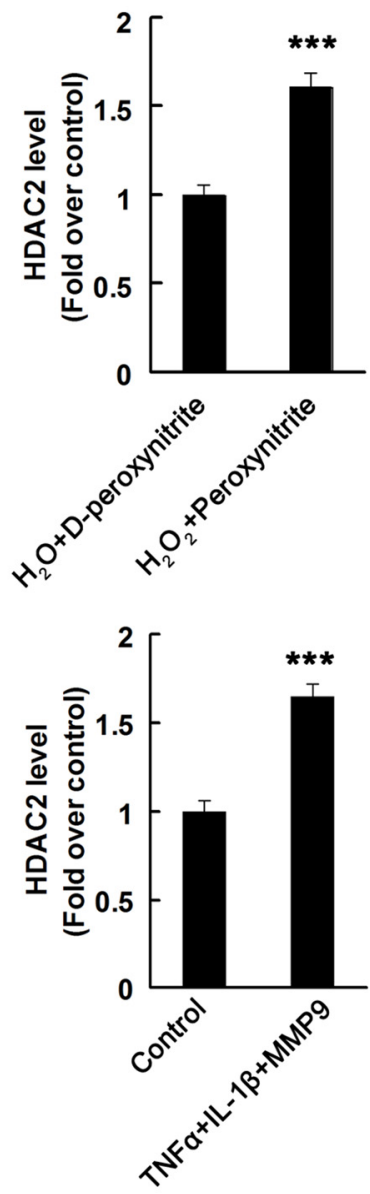

$\mathbf{E}$

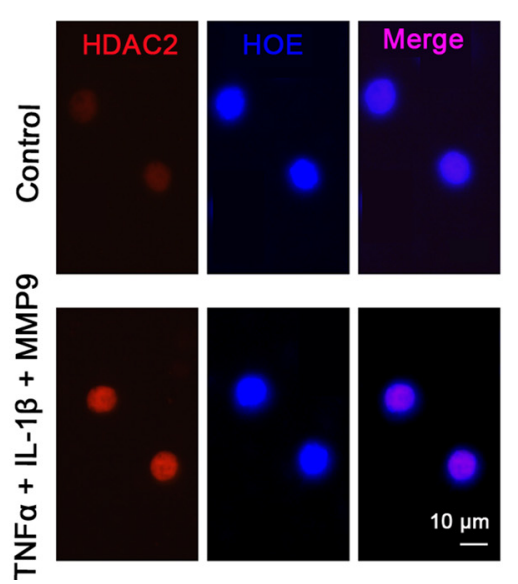

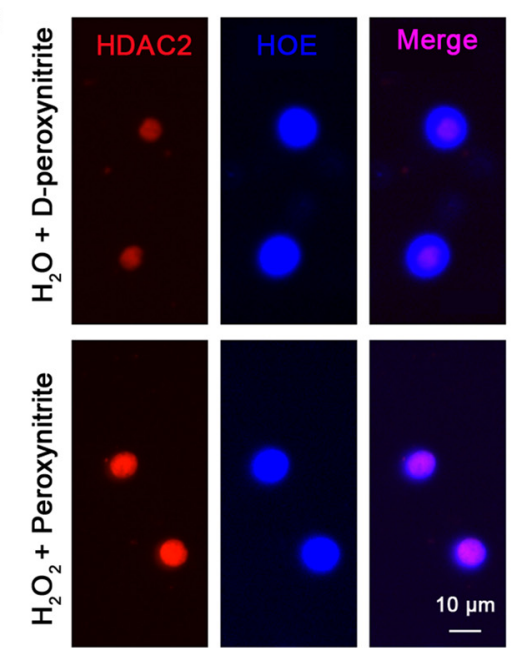

Figure 6. Inflammatory factors and free radicals contribute to HDAC2 upregulation in the peri-infarct cortex. $\boldsymbol{A}$, Representative images of immunohistochemical labeling of HDAC2. $\boldsymbol{B}$, Bar graph showing HDAC2 fluorescence intensity in the peri-infarct cortex at $7 \mathrm{~d}$ after stroke $(n=12)$. ${ }^{* *} p=0.007$ (two-tailed $t$ test). Scale bar, $20 \mu \mathrm{m}$. C, Representative immunoblots and bar graph showing HDAC2 level in the cultured cortical neurons incubated with $\mathrm{H}_{2} \mathrm{O}_{2}+$ peroxynitrite for $1 \mathrm{~h}$, and assessed $8 \mathrm{~h}$ later $(n=3) .{ }^{* *} p=0.0045$ (two-tailed $t$ test). D, Representative immunofluorescence images (left) and bar graph (right) showing HDAC2 level in the cultured cortical neurons incubated with $\mathrm{H}_{2} \mathrm{O}_{2}+$ peroxynitrite for $1 \mathrm{~h}$, and assessed $8 \mathrm{~h}$ later $\left(n=24\right.$ and $n=27$ neurons for $\mathrm{H}_{2} \mathrm{O}+$ D-peroxynitrite and $\mathrm{H}_{2} \mathrm{O}_{2}+$ peroxynitrite, respectively). ${ }^{* *} p<0.001$ (two-tailed $t$ test). $\boldsymbol{E}$, Representative immunoblots and bar graph showing HDAC2 level in the cultured cortical neurons incubated with TNF $\alpha+\mathrm{IL}-1 \beta+$ MMP9 for $24 \mathrm{~h}(n=4) .{ }^{* *} p=0.0061$ (two-tailed $t$ test). $\boldsymbol{F}$, Representative immunofluorescence images (left) and bar graph (right) showing HDAC2 level in the cultured cortical neurons incubated with TNF $\alpha+\mathrm{IL}-1 \beta+\operatorname{MMP9}$ for $24 \mathrm{~h}$ ( $n=30$ and $n=27$ neurons for vehicle and TNF $\alpha+\mathrm{IL}-1 \beta+$ MMP9, respectively). ${ }^{* * *} p<0.001$ (two-tailed $t$ test). $G$, Representative immunoblots and bar graph showing HDAC2 level in the cultured cortical neurons incubated with NMDA for $1 \mathrm{~h}(n=3)$. $p>0.05$ (two-tailed $t$ test). 
A

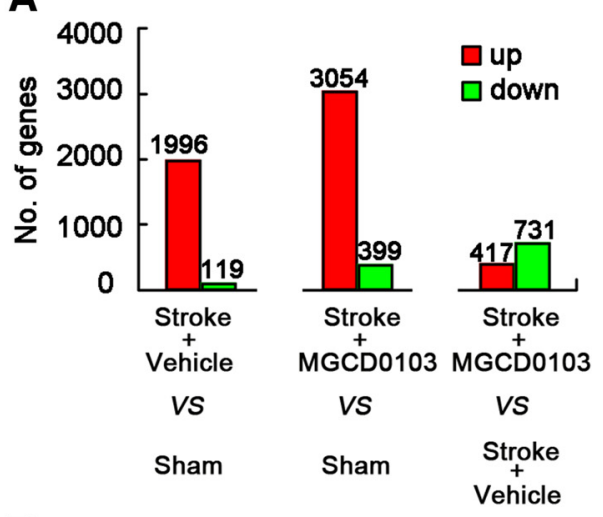

B

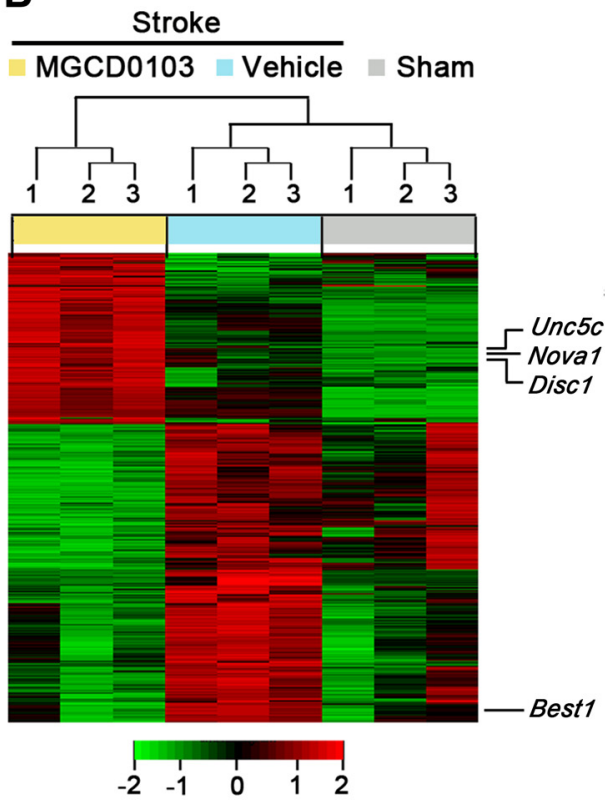

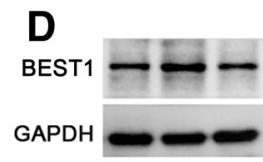

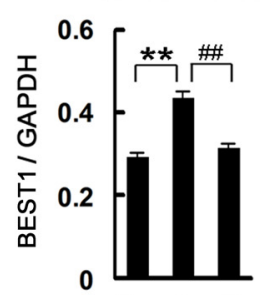

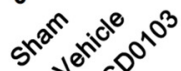

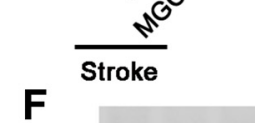

$\mathbf{F}$
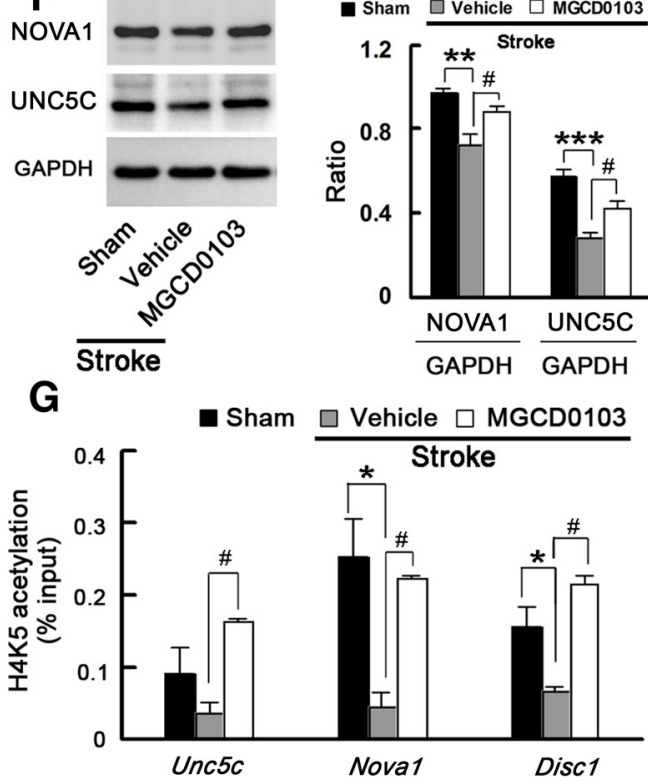

- Sham $\square$ Vehicle $\square$ MGCD0103
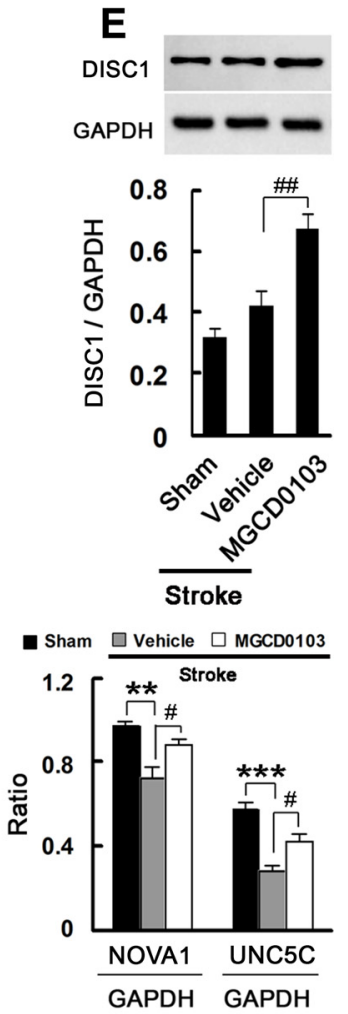

C
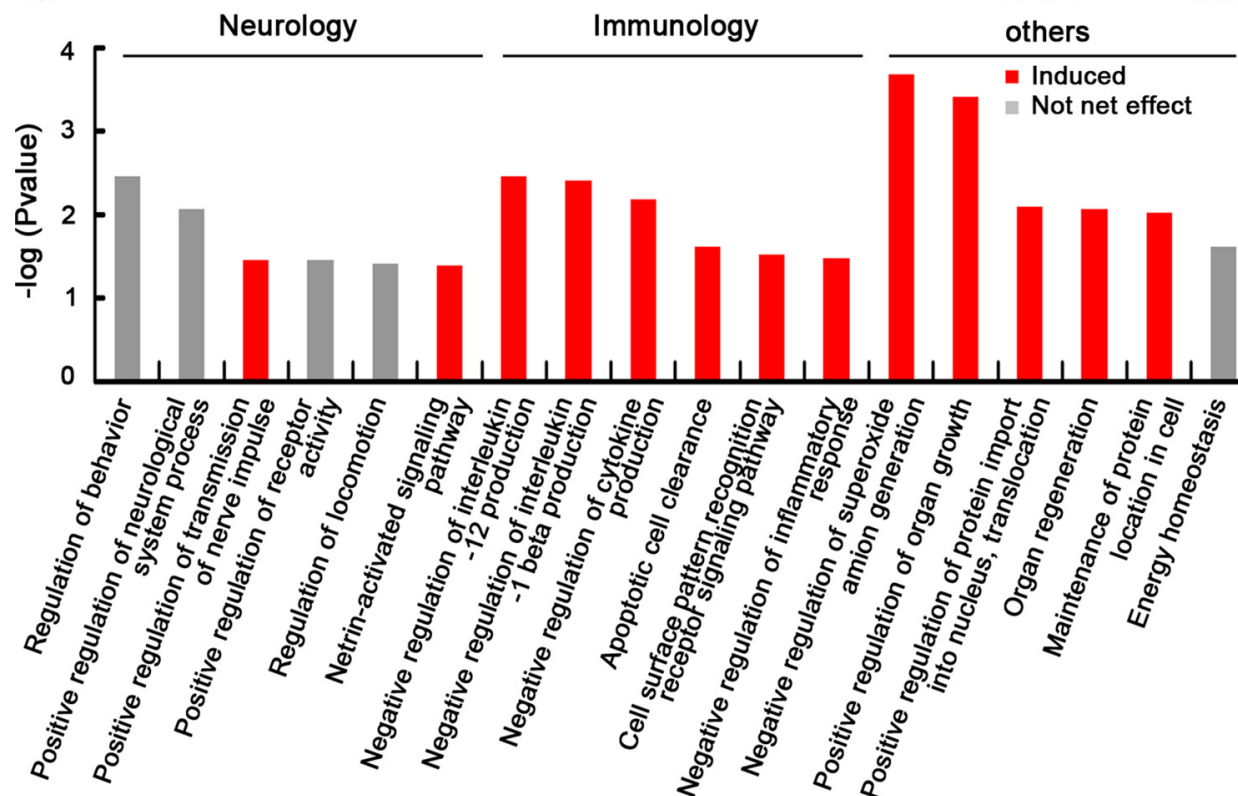
A
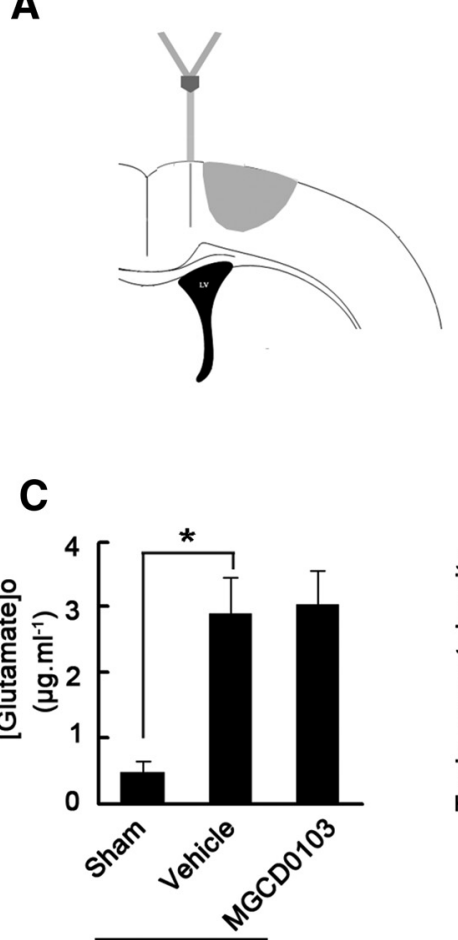

Stroke

\section{F}

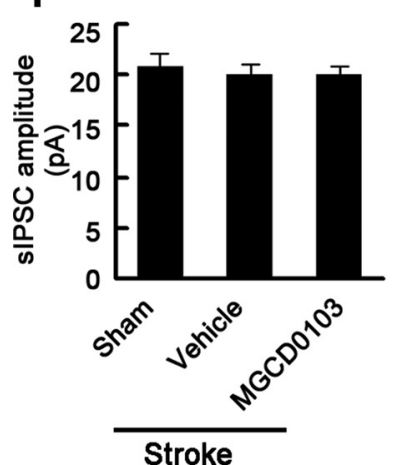

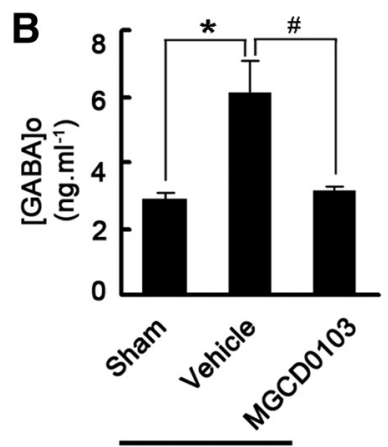

Stroke

E

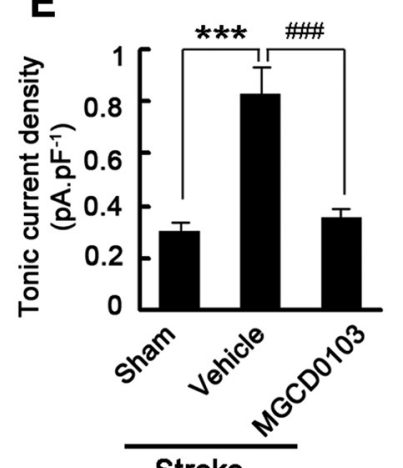

Stroke

G

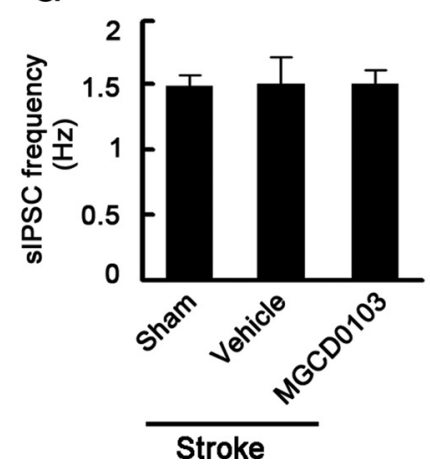

D

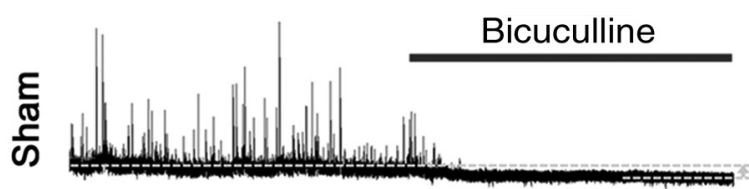

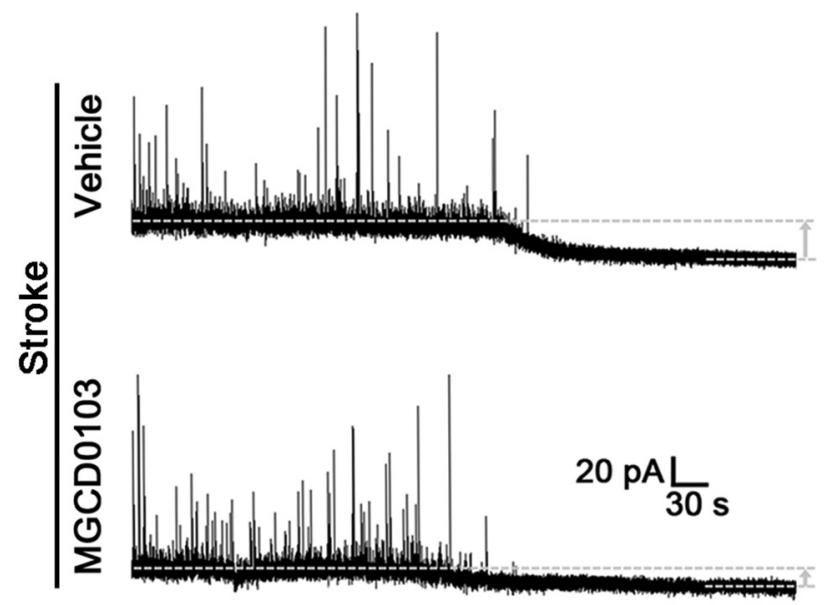

H

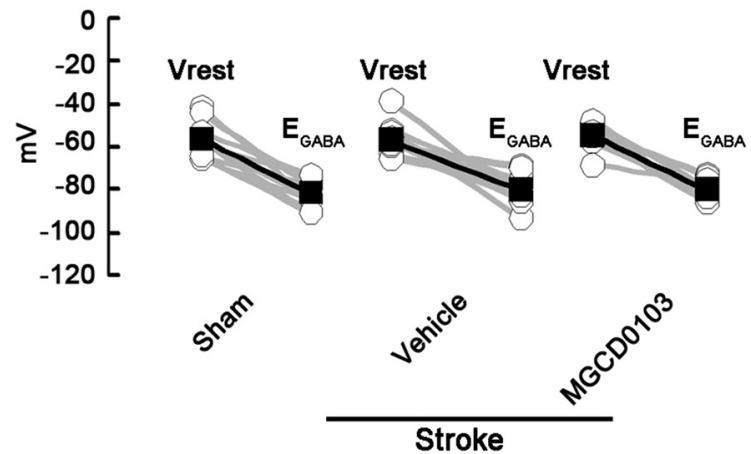

Figure 8. Inhibiting Class I HDACs leads to a decrease in GABA tonic inhibition $\left(I_{\text {tonic }}\right)$. A, Schematic diagram showing in vivo microdialysis. $B$, Bar graph showing [GABA]o in the peri-infarct cortex at $8 \mathrm{~d}$ after stroke $\left(n=4, n=5\right.$, and $n=5$ for sham, vehicle, and MGCD0103, respectively). $F_{(2,11)}=7.68 .{ }^{*} p=0.019$, sham versus vehicle (ANOVA). ${ }^{*} p=0.022$, vehicle versus MGCD0103 (ANOVA). [GABA]0, Extracellular concentrations of GABA. C, Bar graph showing [glutamate] o in the peri-infarct cortex at $8 \mathrm{~d}$ after stroke $(n=4, n=5$, and $n=5$ for sham, vehicle, and MGCD0103, respectively). $F_{(2,11)}=8.40 .{ }^{*} p=0.016$, sham versus vehicle. $p=0.975$, vehicle versus $M G C D 0103$. [Glutamate]0, Extracellular concentrations of glutamate. $D$, Representative recordings of tonic current. $\boldsymbol{E}$, Bar graph showing tonic current density from the neurons in the peri-infarct cortex at $8 \mathrm{~d}$ after stroke $(n=20, n=21$, and $n=19$ for sham, vehicle, and MGCD0103, respectively). $F_{(2,57)}=14.59 .^{* * *} p<0.001$ (ANOVA). ${ }^{\# \# \#} p<0.001$ (ANOVA). $\boldsymbol{F}$, Bar graph showing amplitude of sIPSCs in the peri-infarct cortex at $8 \mathrm{~d}$ after stroke $(n=20, n=21$, and $n=19$ neurons from 8 or 9 animals for sham, vehicle, and MGCD0103, respectively). $F_{(2,57)}=0.19 . p=1.0, M G C D 0103$ versus vehicle (ANOVA). G, Bar graph showing frequency of sIPSCs in the peri-infarct cortex at $8 \mathrm{~d}$ after stroke ( $n=20, n=21$, and $n=19$ neurons from 8 or 9 animals for sham, vehicle, and MGCD0103, respectively). $F_{(2,57)}=0.01 . p=0.999$, MGCD0103 versus vehicle (ANOVA). $\boldsymbol{H}$, Resting membrane potential $\left(\mathrm{V}_{\text {ress }}\right)$ and GABA reversal potential $\left(\mathrm{E}_{\mathrm{GABA}}\right)$ measured using voltage clamps $(-100$ to $100 \mathrm{mV})$ in the cell-attached configuration in sham-, vehicle-, or MGCD0103-treated peri-infarct neurons, showing that neither stroke nor MGCD0103 changed the hyperpolarizing property of GABAergic transmission $(n=9, n=11$, and $n=10$ neurons from 5 or 6 animals for sham,

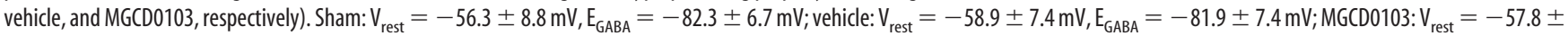
$5.7 \mathrm{mV}, \mathrm{E}_{\mathrm{GABA}}=-83.2 \pm 5.1 \mathrm{mV}\left(\mathrm{V}_{\text {rest: }}:\right.$ ANOVA, $F_{(2,27)}=0.3, p=0.942, \mathrm{MGCD} 0103$ vs vehicle; $\mathrm{E}_{\mathrm{GABA}}: \mathrm{ANOVA}, F_{(2,27)}=0.11, p=0.898, \mathrm{MGCD} 0103$ vs vehicle). B-H, MGCD0103 (1 $\left.\mu \mathrm{m} / 2 \mu \mathrm{l} / \mathrm{d}\right)$ or vehicle was infused into the peri-infarct cortex $5-7 \mathrm{~d}$ after stroke.

$\overline{\text { (Figure legend continued.) this pathway. Gray represents mixed upregulation or downregula- }}$ tion in pathway genes such that there was no net trend. $\boldsymbol{D}-\boldsymbol{F}$, Western blot confirmation of the expression of several neuroplasticity-related genes detected under $\boldsymbol{B}$. G, Quantitative RT-PCR results showing the abundance of $\mathrm{ACH} 4 \mathrm{~K} 5$ at the promoter region of the MGCD0103-induced upregulated genes under $\boldsymbol{B} . \boldsymbol{D}, n=3$, ANOVA, $F_{(2,6)}=26.66 .{ }^{* *} p=0.002 .{ }^{\# \#} p=0.003$. $E$, ANOVA, $n=4, F_{(2,9)}=25.97$. ${ }^{\# \#} p=0.002$. $F$, ANOVA, $n=4$. For NOVA1, $F_{(2,9)}=12.90$. ${ }^{* *} p=0.001,{ }^{*} p=0.032$. For UNC5C, $F_{(2,9)}=36.14 .{ }^{* * *} p<0.001 .{ }^{*} p=0.011$. G, ANOVA, $n=4$. For Unc5c, $F_{(2,9)}=5.59 .{ }^{*} p=0.026$. For Nova1, $F_{(2,9)}=8.37 .{ }^{*} p=0.014 .{ }^{*} p=0.03$. For Disc1, $F_{(2,9)}=11.87 .{ }^{*} p=0.048$. ${ }^{\#} p=0.003$. rons and in astrocyte nuclei, whereas HDAC2 is confined to the neuron nuclei and displays an extensive presence in nuclei, cell body, end-feet in astrocytes (Baltan et al., 2011). HDAC1 and HDAC2 not only interact with RE1-silencing transcription factor to form a complex to coregulate global gene expression after stroke (Calderone et al., 2003; Formisano et al., 2007, 2015) but also affect different sets of target genes in brains (Guan et al., 2009; Montgomery et al., 2009). Moreover, expression of HDACs is clearly different among neuronal groups (Takase et al., 2013). 
A

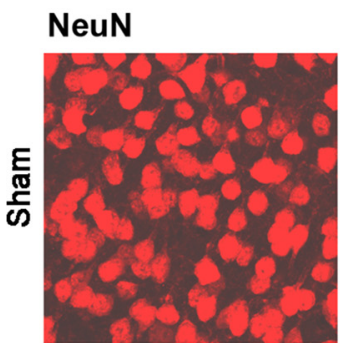

Iba1
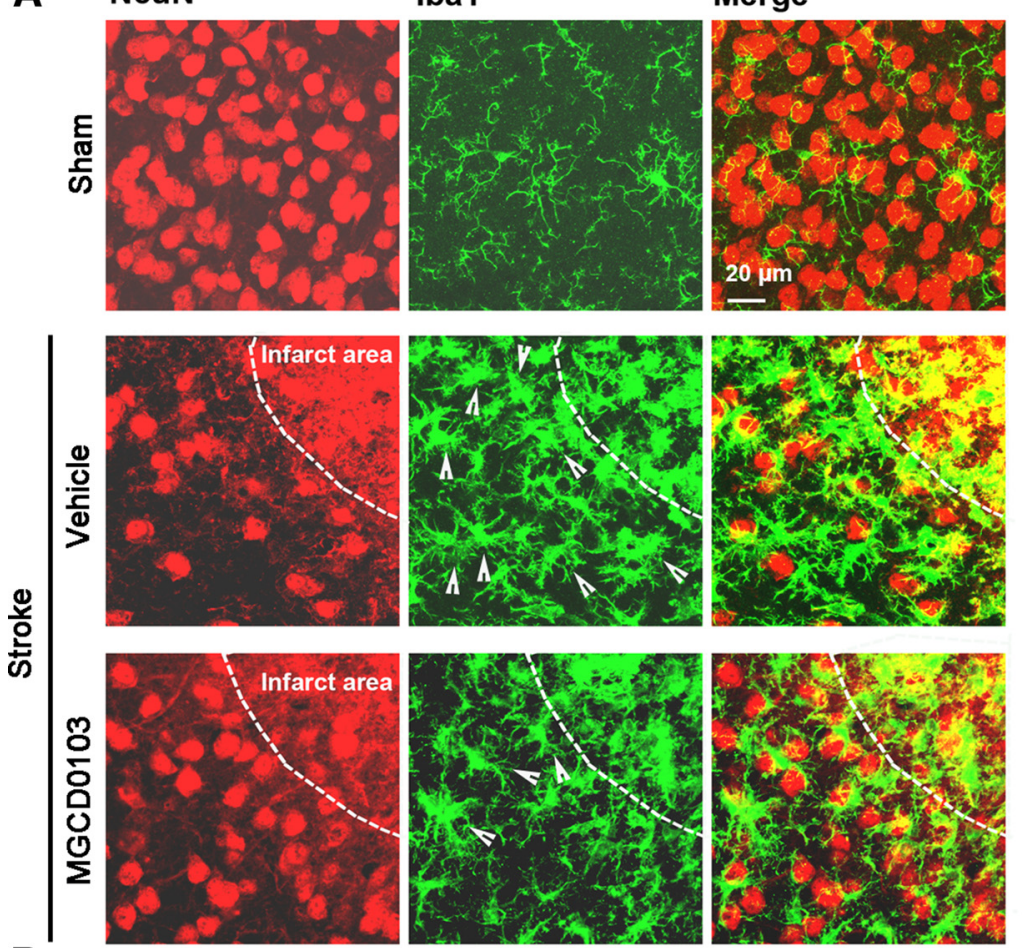

B

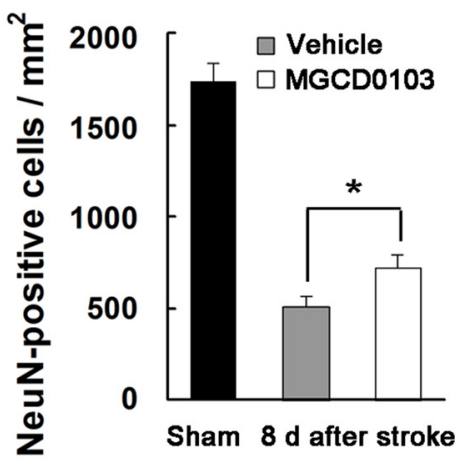

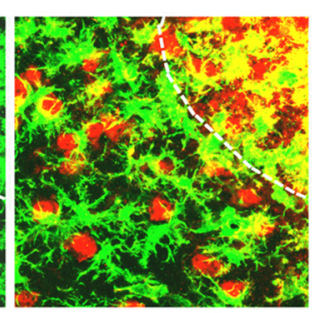

Merge

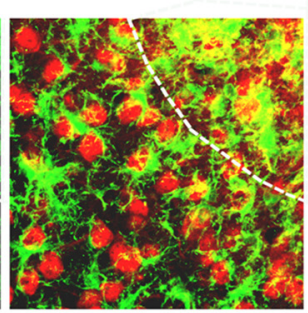

D

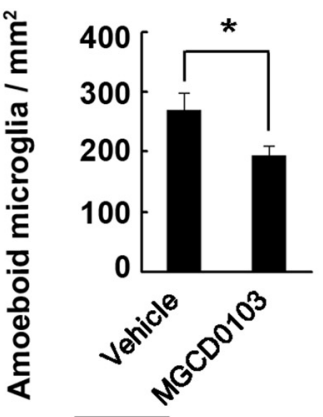

Stroke
C
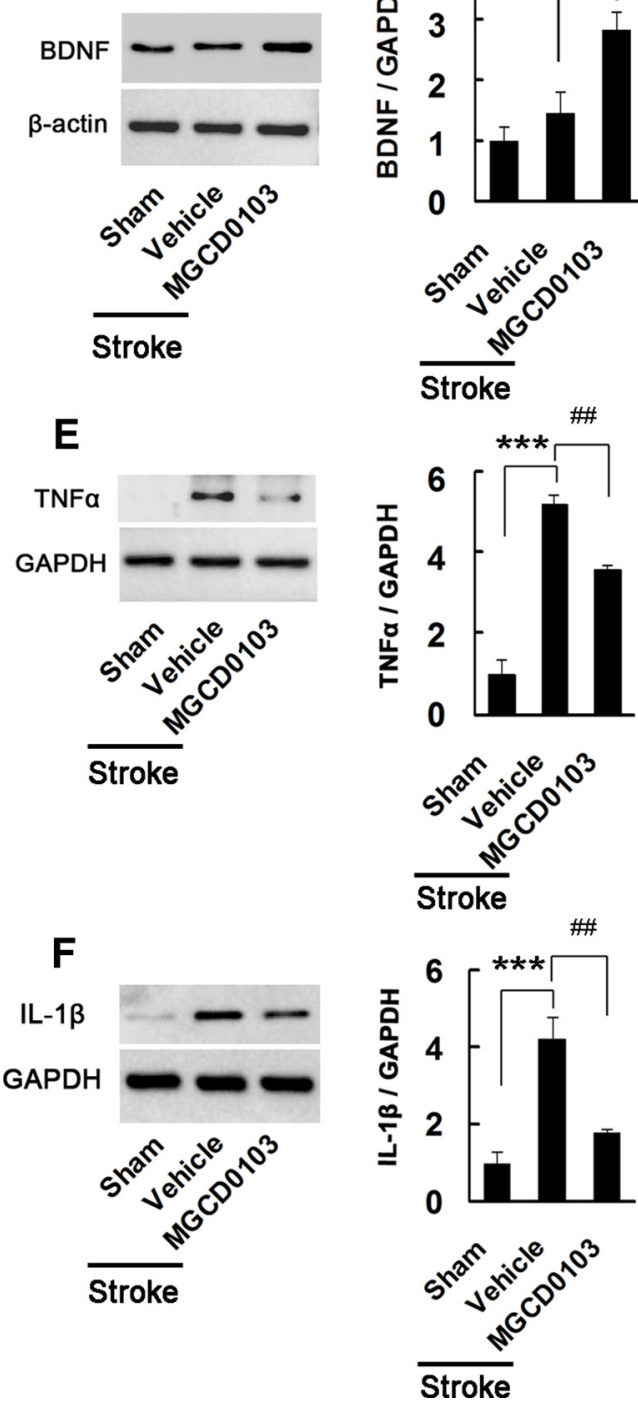

Figure 9. Inhibiting Class I HDACs enhances neurons survival and reduces neuroinflammation in the peri-infarct cortex after stroke. MGCD0103 (1 $\mu \mathrm{m} / 2 \mu \mathrm{l} / \mathrm{d})$ was infused into the peri-infarct cortex 5-7 d, and immunofluorescence and immunoblots were performed at $8 \mathrm{~d}$ after stroke. $A$, Representative images showing $\mathrm{NeuN}^{+}$(mature neuron marker) and lba ${ }^{+}{ }^{+}$(microglia marker) cells in the peri-infarct cortex in MGCD0103- or vehicle-treated mice after stroke. Arrows indicate amoeboid microglia. $\boldsymbol{B}$, Bar graph showing the number of surviving neurons in the peri-infarct cortex at $8 \mathrm{~d}$ after stroke $(n=6) .{ }^{*} p=0.024$ (two-tailed $t$ test). C, Representative immunoblots and bar graph showing levels of BDNF in the peri-infarct cortex at $8 \mathrm{~d}$ after stroke $\left(n=4, \mathrm{ANOVA}, F_{(2,9)}=\right.$ 11.49). ${ }^{*} p=0.024$. $\boldsymbol{D}$, Bar graph showing the number of amoeboid microglia in the peri-infarct cortex after stroke $(n=15) .{ }^{*} p=0.022$ (two-tailed $t$ test). $\boldsymbol{E}$, Representative immunoblots and bar graph showing levels of TNF $\alpha$ in the peri-infarct cortex $\left(n=3\right.$, ANOVA, $\left.F_{(2,6)}=76.94\right) .{ }^{* * *} p<0.001$. ${ }^{\# \#} p=0.009 . F$, Representative immunoblots and bar graph showing levels of IL- $1 \beta$ in the peri-infarct cortex $\left(n=4\right.$, ANOVA, $\left.F_{(2,9)}=21.98\right) .{ }^{* * *} p<0.001 .{ }^{\# \#} p=0.003$.

The window phase for rescuing secondary functional loss could be attributed to a critical period of secondary neurons loss and heightened neuroplasticity after stroke. Many of the genes and proteins that are important for early brain development show limited period of changed expression following stroke (Murphy and Corbett, 2009). Animal and clinical findings have provided evidence for a critical period during which brain is most receptive to modification by rehabilitative experience (Biernaskie et al., 2004; Salter et al., 2006; Lang et al., 2015). Different from the treatment in the early phase of stroke, however, interventions targeting the secondary functional loss phase are not the earlier the better. We found that treatment with TSA during 2-4 d after stroke were ineffective. Consistent with our findings, clinically, very early physical therapy is actually detrimental to stroke recovery (Murphy and Corbett, 2009).
A variety of HDAC inhibitors have been shown to be neuroprotective (Langley et al., 2009; Aune et al., 2015) in the very early phase of stroke. Indeed, there is no evidence that a neuroprotective agent can be effective on acute ischemic stroke beyond $6 \mathrm{~h}$ (Xu and Pan, 2013). The neruoprotection with narrow time window is not practical for clinical stroke intervention. Here, we provide strong evidence that inhibiting HDAC2 during 5-7 d after stroke improved stroke outcome. The distinctive effect of HDAC2 inhibition could be due to its capability to target diverse pathophysiologies of stroke, as inhibition of Class I HDACs by MGCD0103 promoted cell survival, functional neuroplasticity of surviving neurons, and reduced neuroinflammation. Evidence suggests that inflammation induces changes in the GABAergic neurotransmitter system and GABAergic signaling exerts a reciprocal influence over neuroinflammatory processes (Crowley et 
al., 2016). We showed here that Class I HDAC inhibition leads to reductions in production of free radicals and inflammatory factors and in expression of BEST1, and also contributes to the reduced release of GABA and GABA-mediated $I_{\text {tonic }}$. Moreover, free radicals and inflammatory factors caused HDAC2 upregulation after stroke. Thus, interaction between GABAergic signaling and free radicals and inflammatory factors may account for the mechanisms underlying the role of Class I HDACs in stroke recovery. Although there are several studies showing that delayed treatment promotes functional recovery after stroke (Clarkson et al., 2010; Luo et al., 2014; Zhou et al., 2015), to our knowledge, this is the first time to reveal a defined time window for rescuing functional loss in the delayed phase after stroke. With the wide time window in the delayed phase after stroke, the intervention by precisely targeting HDAC2 may bring hope for functional recovery of stroke survivors.

\section{References}

Aune SE, Herr DJ, Kutz CJ, Menick DR (2015) Histone deacetylases exert class-specific roles in conditioning the brain and heart against acute ischemic injury. Front Neurol 6:145. CrossRef Medline

Baltan S, Bachleda A, Morrison RS, Murphy SP (2011) Expression of histone deacetylases in cellular compartments of the mouse brain and the effects of ischemia. Transl Stroke Res 2:411-423. CrossRef Medline

Baskin YK, Dietrich WD, Green EJ (2003) Two effective behavioral tasks for evaluating sensorimotor dysfunction following traumatic brain injury in mice. J Neurosci Methods 129:87-93. CrossRef Medline

Bie B, Wu J, Yang H, Xu JJ, Brown DL, Naguib M (2014) Epigenetic suppression of neuroligin 1 underlies amyloid-induced memory deficiency. Nat Neurosci 17:223-231. CrossRef Medline

Biernaskie J, Chernenko G, Corbett D (2004) Efficacy of rehabilitative experience declines with time after focal ischemic brain injury. J Neurosci 24:1245-1254. CrossRef Medline

Broughton BR, Reutens DC, Sobey CG (2009) Apoptotic mechanisms after cerebral ischemia. Stroke 40:e331-e339. CrossRef Medline

Calderone A, Jover T, Noh KM, Tanaka H, Yokota H, Lin Y, Grooms SY, Regis R, Bennett MV, Zukin RS (2003) Ischemic insults derepress the gene silencer REST in neurons destined to die. J Neurosci 23:2112-2121. Medline

Cavasin MA, Demos-Davies K, Horn TR, Walker LA, Lemon DD, Birdsey N, Weiser-Evans MC, Harral J, Irwin DC, Anwar A, Yeager ME, Li M, Watson PA, Nemenoff RA, Buttrick PM, Stenmark KR, McKinsey TA (2012) Selective Class I histone deacetylase inhibition suppresses hypoxiainduced cardiopulmonary remodeling through an antiproliferative mechanism. Circ Res 110:739-748. CrossRef Medline

Chapman SN, Mehndiratta P, Johansen MC, McMurry TL, Johnston KC, Southerland AM (2014) Current perspectives on the use of intravenous recombinant tissue plasminogen activator ( $\mathrm{tPA}$ ) for treatment of acute ischemic stroke. Vasc Health Risk Manag 10:75-87. CrossRef Medline

Clarkson AN, Huang BS, Macisaac SE, Mody I, Carmichael ST (2010) Reducing excessive GABA-mediated tonic inhibition promotes functional recovery after stroke. Nature 468:305-309. CrossRef Medline

Clarkson AN, Overman JJ, Zhong S, Mueller R, Lynch G, Carmichael ST (2011) AMPA receptor-induced local brain-derived neurotrophic factor signaling mediates motor recovery after stroke. J Neurosci 31:3766-3775. CrossRef Medline

Cronin CA, Sheth KN, Zhao X, Messé SR, Olson DM, Hernandez AF, Bhatt DL, Schwamm LH, Smith EE (2014) Adherence to Third European Cooperative Acute Stroke Study 3- to 4.5-hour exclusions and association with outcome: data from Get with the Guidelines-Stroke. Stroke 45:27452749. CrossRef Medline

Crowley T, Cryan JF, Downer EJ, O'Leary OF (2016) Inhibiting neuroinflammation: the role and therapeutic potential of GABA in neuro-immune interactions. Brain Behav Immun 54:260-277. CrossRef Medline

Eckstein JA, Ammerman GM, Reveles JM, Ackermann BL (2008) Analysis of glutamine, glutamate, pyroglutamate, and GABA in cerebrospinal fluid using ion pairing HPLC with positive electrospray LC-MS/MS. J Neurosci Methods 171:190-196. CrossRef Medline

Formisano L, Noh KM, Miyawaki T, Mashiko T, Bennett MV, Zukin RS (2007) Ischemic insults promote epigenetic reprogramming of mu opi- oid receptor expression in hippocampal neurons. Proc Natl Acad Sci U S A 104:4170-4175. CrossRef Medline

Formisano L, Guida N, Valsecchi V, Cantile M, Cuomo O, Vinciguerra A, Laudati G, Pignataro G, Sirabella R, Di Renzo G, Annunziato L (2015) Sp3/REST/HDAC1/HDAC2 complex represses and Sp1/HIF-1/p300 complex activates ncxl gene transcription, in brain ischemia and in ischemic brain preconditioning, by epigenetic mechanism. J Neurosci 35 : 7332-7348. CrossRef Medline

Ge S, Goh EL, Sailor KA, Kitabatake Y, Ming GL, Song H (2006) GABA regulates synaptic integration of newly generated neurons in the adult brain. Nature 439:589-593. CrossRef Medline

Gräff J, Joseph NF, Horn ME, Samiei A, Meng J, Seo J, Rei D, Bero AW, Phan TX, Wagner F, Holson E, Xu J, Sun J, Neve RL, Mach RH, Haggarty SJ, Tsai LH (2014) Epigenetic priming of memory updating during reconsolidation to attenuate remote fear memories. Cell 156:261-276. CrossRef Medline

Guan JS, Haggarty SJ, Giacometti E, Dannenberg JH, Joseph N, Gao J, Nieland TJ, Zhou Y, Wang X, Mazitschek R, Bradner JE, DePinho RA, Jaenisch R, Tsai LH (2009) HDAC2 negatively regulates memory formation and synaptic plasticity. Nature 459:55-60. CrossRef Medline

Hiu T, Farzampour Z, Paz JT, Wang EH, Badgely C, Olson A, Micheva KD, Wang G, Lemmens R, Tran KV, Nishiyama Y, Liang X, Hamilton SA, O’Rourke N, Smith SJ, Huguenard JR, Bliss TM, Steinberg GK (2016) Enhanced phasic GABA inhibition during the repair phase of stroke: a novel therapeutic target. Brain 139:468-480. CrossRef Medline

Iwasato T, Datwani A, Wolf AM, Nishiyama H, Taguchi Y, Tonegawa S, Knöpfel T, Erzurumlu RS, Itohara S (2000) Cortex-restricted disruption of NMDAR1 impairs neuronal patterns in the barrel cortex. Nature 406: 726-731. CrossRef Medline

Jo S, Yarishkin O, Hwang YJ, Chun YE, Park M, Woo DH, Bae JY, Kim T, Lee J, Chun H, Park HJ, Lee DY, Hong J, Kim HY, Oh SJ, Park SJ, Lee H, Yoon BE, Kim Y, Jeong Y, et al. (2014) GABA from reactive astrocytes impairs memory in mouse models of Alzheimer's disease. Nat Med 20:886-896. CrossRef Medline

Kim D, Frank CL, Dobbin MM, Tsunemoto RK, Tu W, Peng PL, Guan JS, Lee BH, Moy LY, Giusti P, Broodie N, Mazitschek R, Delalle I, Haggarty SJ, Neve RL, Lu Y, Tsai LH (2008) Deregulation of HDAC1 by p25/Cdk5 in neurotoxicity. Neuron 60:803-817. CrossRef Medline

Krämer OH (2009) HDAC2: a critical factor in health and disease. Trends Pharmacol Sci 30:647-655. CrossRef Medline

Lang CE, Lohse KR, Birkenmeier RL (2015) Dose and timing in neurorehabilitation: prescribing motor therapy after stroke. Curr Opin Neurol 28: 549-555. CrossRef Medline

Langley B, Brochier C, Rivieccio MA (2009) Targeting histone deacetylases as a multifaceted approach to treat the diverse outcomes of stroke. Stroke 40:2899-2905. CrossRef Medline

Lee JK, Kim JE, Sivula M, Strittmatter SM (2004) Nogo receptor antagonism promotes stroke recovery by enhancing axonal plasticity. J Neurosci 24:6209-6217. CrossRef Medline

Lee S, Yoon BE, Berglund K, Oh SJ, Park H, Shin HS, Augustine GJ, Lee CJ (2010) Channel-mediated tonic GABA release from glia. Science 330: 790-796. CrossRef Medline

Levine SR, Khatri P, Broderick JP, Grotta JC, Kasner SE, Kim D, Meyer BC, Panagos P, Romano J, Scott P (2013) Review, historical context, and clarifications of the NINDS rt-PA stroke trials exclusion criteria: 1 . Rapidly improving stroke symptoms. Stroke 44:2500-2505. CrossRef Medline

Li S, Nie EH, Yin Y, Benowitz LI, Tung S, Vinters HV, Bahjat FR, StenzelPoore MP, Kawaguchi R, Coppola G, Carmichael ST (2015) GDF10 is a signal for axonal sprouting and functional recovery after stroke. Nat Neurosci 18:1737-1745. CrossRef Medline

Lo EH (2014) 2013 Thomas Willis Award Lecture: causation and collaboration for stroke research. Stroke 45:305-308. CrossRef Medline

Lobera M, Madauss KP, Pohlhaus DT, Wright QG, Trocha M, Schmidt DR, Baloglu E, Trump RP, Head MS, Hofmann GA, Murray-Thompson M, Schwartz B, Chakravorty S, Wu Z, Mander PK, Kruidenier L, Reid RA, Burkhart W, Turunen BJ, Rong JX, et al. (2013) Selective Class IIa histone deacetylase inhibition via a nonchelating zinc-binding group. Nat Chem Biol 9:319-325. CrossRef Medline

Luo CX, Jin X, Cao CC, Zhu MM, Wang B, Chang L, Zhou QG, Wu HY, Zhu DY (2010) Bidirectional regulation of neurogenesis by neuronal nitric 
oxide synthase derived from neurons and neural stem cells. Stem Cells 28:2041-2052. CrossRef Medline

Luo CX, Lin YH, Qian XD, Tang Y, Zhou HH, Jin X, Ni HY, Zhang FY, Qin C, Li F, Zhang Y, Wu HY, Chang L, Zhu DY (2014) Interaction of nNOS with PSD-95 negatively controls regenerative repair after stroke. J Neurosci 34:13535-13548. CrossRef Medline

Mendis S, Davis S, Norrving B (2015) Organizational update: the World Health Organization Global Status Report on Noncommunicable Diseases 2014: one more landmark step in the combat against stroke and vascular disease. Stroke 46:e121-e122. CrossRef Medline

Montgomery RL, Hsieh J, Barbosa AC, Richardson JA, Olson EN (2009) Histone deacetylases 1 and 2 control the progression of neural precursors to neurons during brain development. Proc Natl Acad Sci U S A 106: 7876-7881. CrossRef Medline

Moretti A, Ferrari F, Villa RF (2015) Neuroprotection for ischaemic stroke: current status and challenges. Pharmacol Ther 146:23-34. CrossRef Medline

Murphy TH, Corbett D (2009) Plasticity during stroke recovery: from synapse to behaviour. Nat Rev Neurosci 10:861-872. CrossRef Medline

Neher JJ, Emmrich JV, Fricker M, Mander PK, Théry C, Brown GC (2013) Phagocytosis executes delayed neuronal death after focal brain ischemia. Proc Natl Acad Sci U S A 110:E4098-E4107. CrossRef Medline

Norkett R, Modi S, Birsa N, Atkin TA, Ivankovic D, Pathania M, Trossbach SV, Korth C, Hirst WD, Kittler JT (2016) DISC1-dependent regulation of mitochondrial dynamics controls the morphogenesis of complex neuronal dendrites. J Biol Chem 291:613-629. CrossRef Medline

Nott A, Watson PM, Robinson JD, Crepaldi L, Riccio A (2008) S-Nitrosylation of histone deacetylase 2 induces chromatin remodelling in neurons. Nature 455: 411-415. CrossRef Medline

Ohsawa I, Ishikawa M, Takahashi K, Watanabe M, Nishimaki K, Yamagata K, Katsura K, Katayama Y, Asoh S, Ohta S (2007) Hydrogen acts as a therapeutic antioxidant by selectively reducing cytotoxic oxygen radicals. Nat Med 13:688-694. CrossRef Medline

Peng S, Zhao S, Yan F, Cheng J, Huang L, Chen H, Liu Q, Ji X, Yuan Z (2015) HDAC2 selectively regulates FOXO3a-mediated gene transcription during oxidative stress-induced neuronal cell death. J Neurosci 35:12501259. CrossRef Medline

Robert T, Vanoli F, Chiolo I, Shubassi G, Bernstein KA, Rothstein R, Botrugno OA, Parazzoli D, Oldani A, Minucci S, Foiani M (2011) HDACs link the DNA damage response, processing of double-strand breaks and autophagy. Nature 471:74-79. CrossRef Medline

Salisbury CM, Cravatt BF (2007) Activity-based probes for proteomic profiling of histone deacetylase complexes. Proc Natl Acad Sci U S A 104: 1171-1176. CrossRef Medline

Salter K, Jutai J, Hartley M, Foley N, Bhogal S, Bayona N, Teasell R (2006)
Impact of early vs delayed admission to rehabilitation on functional outcomes in persons with stroke. J Rehabil Med 38:113-117. CrossRef Medline

Shichita T, Sugiyama Y, Ooboshi H, Sugimori H, Nakagawa R, Takada I, Iwaki T, Okada Y, Iida M, Cua DJ, Iwakura Y, Yoshimura A (2009) Pivotal role of cerebral interleukin-17-producing $\gamma \delta \mathrm{T}$ cells in the delayed phase of ischemic brain injury. Nat Med 15:946-950. CrossRef Medline

Shimazu T, Hirschey MD, Newman J, He W, Shirakawa K, Le Moan N, Grueter CA, Lim H, Saunders LR, Stevens RD, Newgard CB, Farese RV Jr, de Cabo R, Ulrich S, Akassoglou K, Verdin E (2013) Suppression of oxidative stress by $\beta$-hydroxybutyrate, an endogenous histone deacetylase inhibitor. Science 339:211-214. CrossRef Medline

Sigler A, Mohajerani MH, Murphy TH (2009) Imaging rapid redistribution of sensory-evoked depolarization through existing cortical pathways after targeted stroke in mice. Proc Natl Acad Sci U S A 106:11759-11764. CrossRef Medline

Störchel PH, Thümmler J, Siegel G, Aksoy-Aksel A, Zampa F, Sumer S, Schratt G (2015) A large-scale functional screen identifies Noval and Ncoa3 as regulators of neuronal miRNA function. EMBO J 34:2237-2254. CrossRef Medline

Takase K, Oda S, Kuroda M, Funato H (2013) Monoaminergic and neuropeptidergic neurons have distinct expression profiles of histone deacetylases. PLoS One 8:e58473. CrossRef Medline

Walsh JG, Muruve DA, Power C (2014) Inflammasomes in the CNS. Nat Rev Neurosci 15:84-97. CrossRef Medline

Wetzel-Smith MK, Hunkapiller J, Bhangale TR, Srinivasan K, Maloney JA, Atwal JK, Sa SM, Yaylaoglu MB, Foreman O, Ortmann W, Rathore N, Hansen DV, Tessier-Lavigne M, Mayeux R, Pericak-Vance M, Haines J, Farrer LA, Schellenberg GD, Goate A, Behrens TW, et al. (2014) A rare mutation in UNC5C predisposes to late-onset Alzheimer's disease and increases neuronal cell death. Nat Med 20:1452-1457. CrossRef Medline

Xu SY, Pan SY (2013) The failure of animal models of neuroprotection in acute ischemic stroke to translate to clinical efficacy. Med Sci Monit Basic Res 19:37-45. CrossRef Medline

Yang XJ, Seto E (2008) The Rpd3/Hda1 family of lysine deacetylases: from bacteria and yeast to mice and men. Nat Rev Mol Cell Biol 9:206-218. CrossRef Medline

Zhou HH, Tang Y, Zhang XY, Luo CX, Gao LY, Wu HY, Chang L, Zhu DY (2015) Delayed administration of Tat-HA-NR2B9c promotes recovery after stroke in rats. Stroke 46:1352-1358. CrossRef Medline

Zhou L, Li F, Xu HB, Luo CX, Wu HY, Zhu MM, Lu W, Ji X, Zhou QG, Zhu DY (2010) Treatment of cerebral ischemia by disrupting ischemiainduced interaction of nNOS with PSD-95. Nat Med 16:1439-1443. CrossRef Medline 